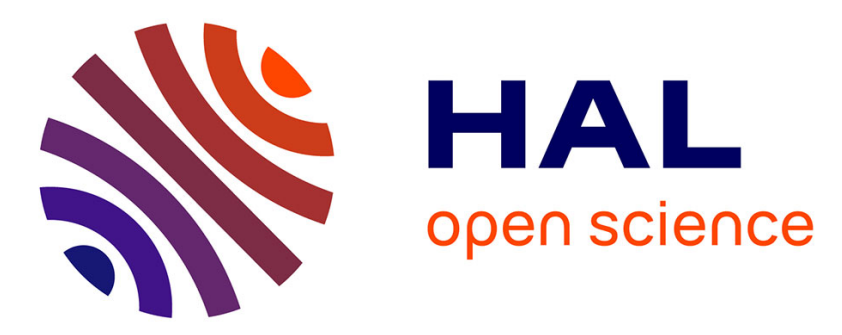

\title{
Single-site and nano-confined photocatalysts designed in porous materials for environmental uses and solar fuels
}

Hiromi Yamashita, Kohsuke Mori, Yasutaka Kuwahara, Takashi Kamegawa, Meicheng Wen, Priyanka Verma, Michel Che

\section{- To cite this version:}

Hiromi Yamashita, Kohsuke Mori, Yasutaka Kuwahara, Takashi Kamegawa, Meicheng Wen, et al.. Single-site and nano-confined photocatalysts designed in porous materials for environmental uses and solar fuels. Chemical Society Reviews, 2018, 47 (22), pp.8072-8096. hal-01959036

\section{HAL Id: hal-01959036 \\ https://hal.sorbonne-universite.fr/hal-01959036}

Submitted on 18 Dec 2018

HAL is a multi-disciplinary open access archive for the deposit and dissemination of scientific research documents, whether they are published or not. The documents may come from teaching and research institutions in France or abroad, or from public or private research centers.
L'archive ouverte pluridisciplinaire HAL, est destinée au dépôt et à la diffusion de documents scientifiques de niveau recherche, publiés ou non, émanant des établissements d'enseignement et de recherche français ou étrangers, des laboratoires publics ou privés. 


\title{
Single-site and nano-confined photocatalysts designed in porous materials for environmental uses and solar fuels
}

\author{
Hiromi Yamashita, (D)*ab Kohsuke Mori, (D)*abc Yasutaka Kuwahara, (D) ab \\ Takashi Kamegawa, (D) ad Meicheng Wen, ${ }^{a}$ Priyanka Verma ${ }^{\text {a }}{ }^{\text {and }}$ anchel Che ${ }^{* e}$
}

\begin{abstract}
Slica-based micro-, meso-, macro-porous materials offer attractive routes for designing single-site photocatalysts, supporting semiconducting nanoparticles, anchoring light-responsive metal complexes, and encapsulating metal nanoparticles to drive photochemical reactions by taking advantage of their large surface area, controllable pore channels, remarkable transparency to UV/vis and tailorable physicochemical surface characteristics. This review mainly focuses on the fascinating photocatalytic properties of silica-supported $\mathrm{Ti}$ catalysts from single-site catalysts to nanoparticles, their surface-chemistry engineering, such as the hydrophobic modification and synthesis of thin films, and the fabrication of nanocatalysts including morphology controlled plasmonic nanostructures with localized surface plasmon resonance. The hybridization of visible-light responsive metal complexes with porous materials for the construction of functional inorganic-organic supramolecular photocatalysts is also included. In addition, the latest progress in the application of MOFs as excellent hosts for designing photocatalytic systems is described.
\end{abstract}

${ }^{a}$ Division of Materials and Manufacturing Science, Graduate School of Engineering, Osaka University, Osaka, 565-0871, Japan.

E-mail: yamashita@mat.eng.osaka-u.ac.jp,mori@mat.eng.osaka-u.ac.jp

${ }^{\mathrm{b}}$ Unit of Elements Strategy Initiative for Catalysts \& Batteries (ESICB),

Kyoto University, Kyoto, 615-8245, Japan

c JST, PRESTO, 4-1-8 HonCho, Kawaguchi, Saitama, 332-0012, Japan

${ }^{\mathrm{d}}$ Nanoscience and Nanotechnology Research Center, Osaka Prefecture University, 1-2 Gakuencho, Nakaku, Sakai, Osaka 599-8570, Japan

${ }^{\mathrm{e}}$ Institut Universitaire de France and Laboratoire de Réactivité de Surface, Université Pierre et Marie Curie-Paris 6, CNRS-UMR 7197, Paris, France. E-mail: michel.che@upmc.fr

\section{Introduction}

To satisfy the ever-growing energy demands and the environmental issues simultaneously, the development of green technology is of paramount importance. The exten sive research and practical applications carried out in the field of photocatalysis (converting solar energy into chemical energy) are essential missions to solve the above-mentioned issues. ${ }^{1-6}$ Its mainstream

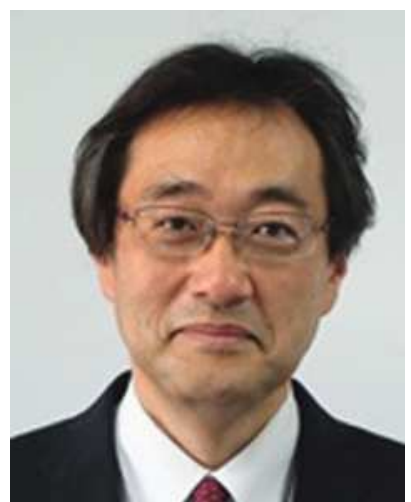

Hiromi Yamashita
Hiromi Yamashita has been a professor of Osaka University since 2004. He received his $\mathrm{PhD}$ degree from Kyoto University in 1987. He was an assistant professor of Tohoku University, an associate professor of Osaka Prefecture University, and an invited professor of Pierre and Marie Curie University (UPMC). $\mathrm{He}$ was also a visiting research fellow of Pennsylvania State University, the University of Texas at Austin, and the California Institute of Technology. His research interests include the design of single-site photocatalysts and nanostructured catalysts.

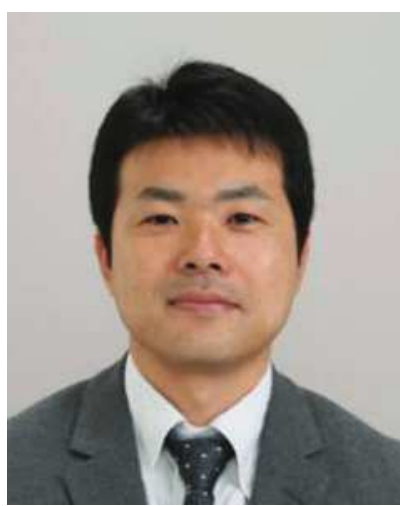

Kohsuke Mori
Kohsuke Mori received his $\mathrm{PhD}$ degree from the Graduate School of Engineering Science at Osaka University under the supervision of Prof. K. Kaneda in 2003. In 2004, he joined Prof. T. Don Tilley's group at the University of California, Berkeley, as a postdoctoral fellow. He moved to the current faculty in 2005 and then became an associate professor in 2009. His current research interests focus on hybrid photocatalysts based on visiblelight-responsive metal complexes, metal and alloy nanoparticle catalysts to establish clean and environmentally-friendly chemical processes, and diesel automobile catalysts. 
is still semiconducting photocatalysts constructed from $\mathrm{TiO}_{2^{-}}$ based materials, which show high photocatalytic activity by producing a large number of excited electrons and holes under light irradiation. ${ }^{7-10}$ These photocatalysts can realize hydrogen production by water splitting, reduction fixation of carbon dioxide, complete oxidative decomposition of pollutants, and many reactions. The down sizing of such semiconducting photocatalysts into nanometer scale fine particles leads to particular intrinsic properties such as quantum size effects. Such fine semiconducting nanoparticles (NPs) exhibit extremely high photocatalytic activity, but photochemical excitation can be performed under shorter wavelength light irradiation. The ultimate small-size limit is an isolated single atom species, which makes them very promising candidates for novel photocatalysts due to the high ratio of low-coordinated metal atoms. However, isolating nanometer scale fine particles and single atom species is still difficult because of the increase of surface free energy upon decreasing the size of the particles. Thus appropriate support materials that strongly interact with nanoparticles and isolated single atom species are necessary in order to maintain their original structures and inherent properties. ${ }^{11}$

Zeolites are silica-based crystals having ordered micropores $(0.5-2.0 \mathrm{~nm}),{ }^{12}$ while mesoporous silica materials are porous frameworks having ordered mesopores $(2-50 \mathrm{~nm}) .{ }^{13,14}$ These porous-silica-based materials can be employed as hosts in the design and functionalization of photocatalytic systems that provide a defined micro-molecular-environmental-field and act as transparent molecular reaction vessels because of the following advantages: (1) their structures and pore sizes can be controlled at atomic and/or molecular levels, (2) the fine connectivity of the pores facilitates the diffusion of reactants within the channels and provides ease of access to the active centers, (3) remarkable transparency in the wide UV/vis wavelength range provides a photochemically inactive surface reaction field, and (4) chemically and thermally stable frameworks with a large number of silanol groups en able functionalization

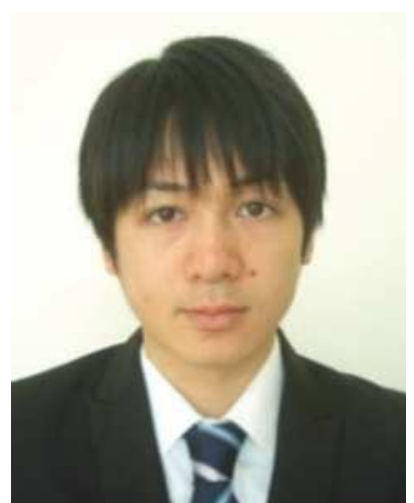

Yasutaka Kuwahara
Yasutaka Kuwahara received his $\mathrm{PhD}$ degree in engineering from Osaka University in 2011. He was a postdoctoral research fellow at the Georgia Institute of Technology, USA in 2011. He had been a researcher at the National Institute of Advanced Industrial Science and Technology (AIST), Japan, from 2012 to 2014. Since 2014, he has been appointed as an assistant professor in Osaka University. His current research interests include the design of nanostructured catalysts with multi-functionalities utilizing porous materials and their applications to green chemical reactions and the conversion of energy and resources.

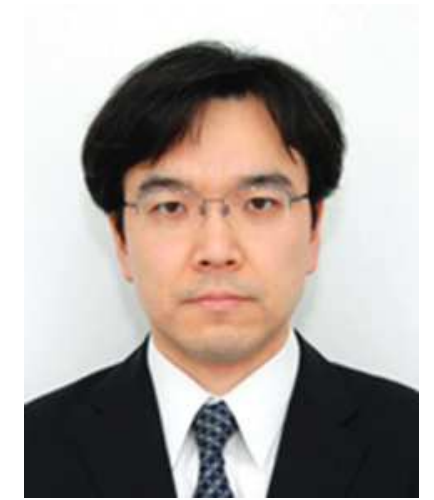

Takashi Kamegawa

Takashi Kamegawa received his $\mathrm{PhD}$ degree in engineering from Osaka Prefecture University under the supervision of Prof. M. Anpo in 2008. He worked in Prof. Yamashita's group in the Graduate School of Engineering at Osaka University as an assistant professor for six years. In 2014, he was appointed as a special lecturer in the Nanoscience and Nanotechnology Research Center at Osaka Prefecture University. His current research interests are the design of nanostructured catalysts and photofunctional nanomaterials for energy and environmental applications.

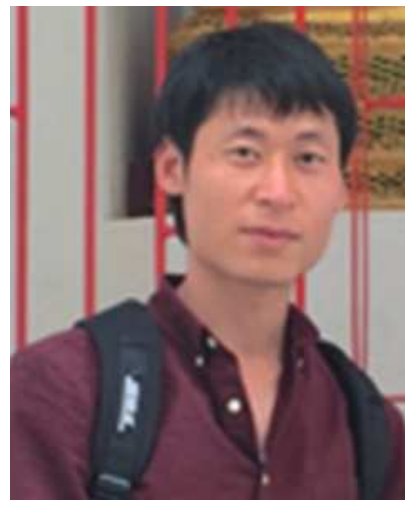

Meicheng Wen
Meicheng Wen received his $\mathrm{PhD}$ degree in engineering from Osaka University under the supervision of Professor Hiromi Yamashita in 2016. He was a specially appointed assistant professor in the Division of Materials and Manufacturing Science at Osaka University from 2016 to 2017. He has been an associate professor at Guangdong University of Technology, China. His research mainly focuses on the preparation of nanomaterials, and their applications in energy conversion and environmental remediation.

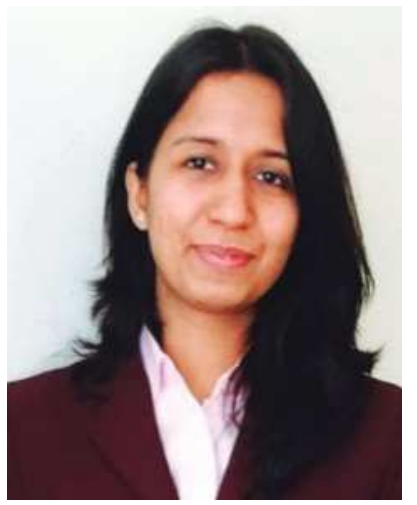

Priyanka Verma
Priyanka Verma did her Bachelor and Master of Science education in India and completed $\mathrm{PhD}$ in engineering under the supervision of Prof. Hiromi Yamashita at Osaka University. She has been working as a specially appointed assistant professor in the Division of Materials and Manufacturing Science at Osaka University since October 2017. Her research interests focus on the design of silverbased plasmonic nanomaterials for various energy and environmental applications. 
with a variety of modifiers. The introduction of $\mathrm{TiO}_{2}$ in to the pore spaces of zeolite or mesoporous silica materials creates nanometer scale ultrafine particles smaller than the pores in a controlled fashion, which exhibit fascinating photocatalytic activity owing to the quantum size effect. The main component of zeolites and mesoporous materials is silica $\left(\mathrm{SiO}_{2}\right)$, but the addition of a metal precursor, such as $\mathrm{Ti}, \mathrm{V}, \mathrm{Cr}$, Mo, or $\mathrm{W}$ atoms, as a constituent element at the synthesis stage enables the replacement of $\mathrm{Si}$ atoms in the frameworks of the nanoporous materials with these heteroatoms in a highly dispersed manner. The heteroatoms incorporated into the silica frameworks have an isolated tetrahedrally-coordinated structure and form a charge transfer type excited state in which excited electrons and positive holes are adjacent to each other under light irradiation.

We have focused on mononuclear photocatalytically active species in an isolated highly dispersed state on a silica substrate or incorporated into silica-based nanoporous materials (zeolite, mesoporous silica), which exhibit quite different photochemical properties from conventional semiconducting photocatalysts due to their unique photoexcited state. By utilizing the pore spaces of the nanoporous materials or the in side of the frameworks, it is also possible to integrate well-defined photo-functional metal complexes with in silica matrices, which can also be included in the category "single-site photocatalysts". 1,15,16 Porous supports, such as zeolites and mesoporous silicas, having a restricted framework, pore structure and nanospaces are the most suitable materials for the design and functionalization of "single-site photocatalysts" for the following reasons: (i) their pore structure can adsorb and concentrate reactants, (ii) the capture of heteroatom s can incorporate single site photocatalysts, (iii) their large surface area can expose plenty of single-site photocatalysts to the outer surface, (iv) colorless transparency can allow the penetration of UV/vis

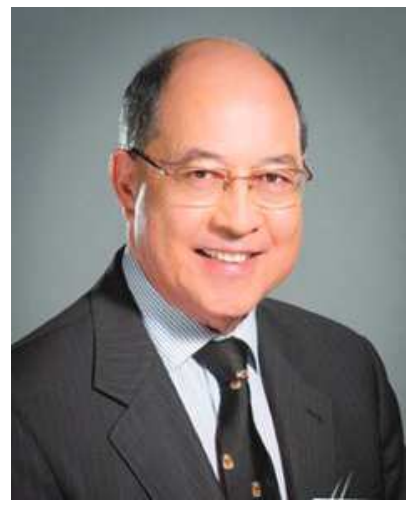

Michel Che
Michel Che obtained his PhD in 1968 (University of Lyon). He was a postdoctoral fellow at Princeton University (1969-1971). He was appointed Professor at Université Pierre et Marie Curie-Paris 6 in 1975 and Senior Member of the Institut Universitaire de France in 1995. He was the PresidentFounder of EFCATS (European Federation of Catalysis Societies) and the President of IACS (International Association of Catalysis Societies) from 2000 to 2004 . He has obtained awards from several countries, notably the UK (the Royal Society of Chemistry's Centenary Lectureship in 2009/2010, the Faraday Lectureship Prize and a Fellow in 2014). He pioneered a molecular approach to catalyst design by bridging the gap between homogeneous and heterogeneous catalysis through the new field of interfacial coordination chemistry. light into the inside of pores, which indispensable for photocatalytic reactions, (v) the surface characteristics can largely be changed with only a small amount of heteroatom addition, and (vi) specified pore spaces can be remarkably influenced by the modifications of the reaction field environment.

In recent years, Metal Organic Frameworks (MOFs) have attracted much attention as new nanoporous materials. ${ }^{17,18}$ They are three dimensional microporous materials with a coordination network structure as well as large surface area far beyond activated carbon and zeolites. It is expected that they be applied to gas adsorption, separation technology, sensors, catalysts, etc. Besides these porous materials, the nano-spaces of interlayer materials, nanosheet materials, porous carbons, and organic functionalized polymers can provide unique reaction fields for nano structured photocatalysts. By fusing the features of single-site photocatalysts and nanoporous materials with controlled structure, size, and surface characteristics of pore spaces, a wide variety of advanced functional materials can also be developed. Furthermore, by utilizing a defined space precisely, it is possible to control the size and morphology of the metal NPs. ${ }^{19}$ Such a methodology is quite useful for the fabrication of size- and morphology-controlled plasmonic metal $\mathrm{NPs}$, such as $\mathrm{Au}, \mathrm{Ag}$, and $\mathrm{Cu}$, because they behave not only as visible-light absorbers but also as catalytically active species that induce photocatalysis directly under visible light irradiation due to their localized surface plasmon resonance (LSPR) properties. ${ }^{20}$ In this case, silica-based supports also act as inert insulators to rule out the support effect because of the difficulty in capturing the hot electrons induced by the plasmonic metal NPs, which helps in the understanding of their intrinsic plasmonic catalytic properties.

In this review, we have highlighted the progress in the design and architecture of silica-supported Ti catalysts from single-site catalysts to NPs and their modulation in terms of surface-chemistry engineering (Fig. 1). Porous silica-based materials, interlayer materials, and organic polymers can also be utilized as promising hosts for designing plasmonic nanocatalysts and integrating photo-responsive metal complexes to drive photochemical reactions for the purpose of solar-energy utilization. Additionally, the latest advances for the application of MOFs in the visible-light-enhanced $\mathrm{H}_{2}$ production from water or hydrogen carriers are summarized. This review aims to present an overview of the design and functionalization of photocatalytic systems with unique characteristics from the viewpoints of not only the support materials but also the catalytically active components with regard to environmental remediation and energy production issues.

\section{Single-site photocatalysts implanted within silica matrices}

Isolated metal oxide ( $\mathrm{Ti}, \mathrm{V}, \mathrm{Cr}$ and Mo-oxide) moieties in a tetrahedral coordination geometry implanted in silica matrixes, such as microporous zeolites and mesoporous silica materials, are called "single-site photocatalysts". ${ }^{1,21-24}$ In the case of 


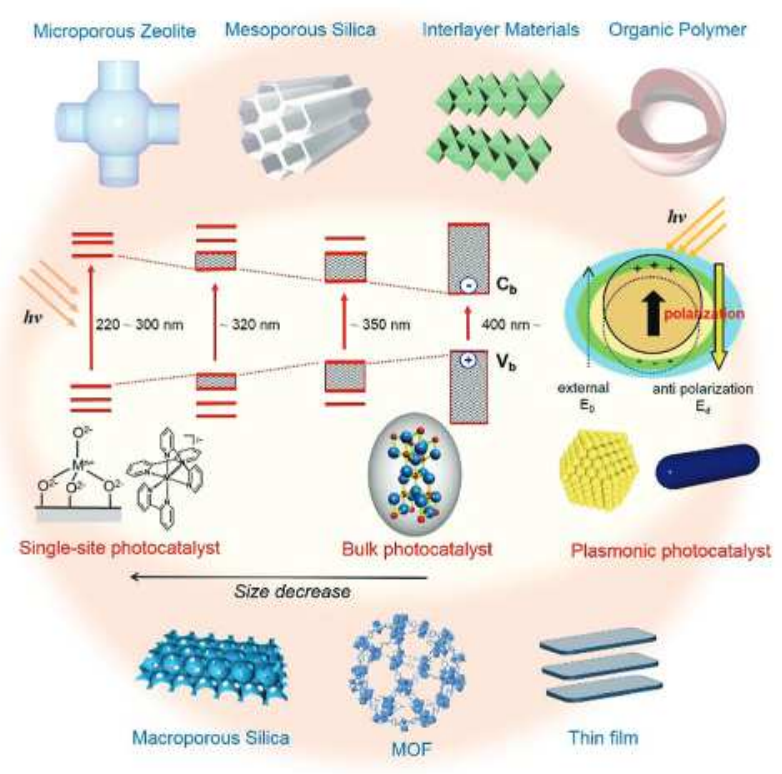

Fig. 1 Change in the band structures with decreasing size of photocatalysts and the schematic illustration of LSPR excitation on plasmonic catalysts confined within porous materials, such as zeolites, mesoporous silica, and MOFs.

semiconducting bulk $\mathrm{TiO}_{2}$ materials, photochemical excitation leads to charge separation in the particle. The generated holes $\left(\mathrm{h}^{+}\right)$in the valence band $\left(\mathrm{v}_{\mathrm{b}}\right)$ and the electrons $\left(\mathrm{e}^{\mathrm{E}}\right)$ in the conduction band can react with electron donors and electron acceptors adsorbed on its surface, respectively. In contrast, the photocatalytic activities of single-site photocatalysts are attributed to the ligand to metal charge transfer (LMCT) processes from the oxygen $\left(\mathrm{O}^{2\left[\mathrm{~F}^{\circ}\right.}\right)$ to $\mathrm{M}^{\mathrm{n}+}$ ions, which resulted in the formation of pairs of trapped hole centers $\left(\mathrm{O}^{\circ}\right)$ and e centers $\left(\mathrm{M}^{(\mathrm{n} \text { (Fi) })}\right)$ (Fig. 2). Such a UV-light induced charge-transfer excited state generated in the single-site photocatalysts, i.e., the excited

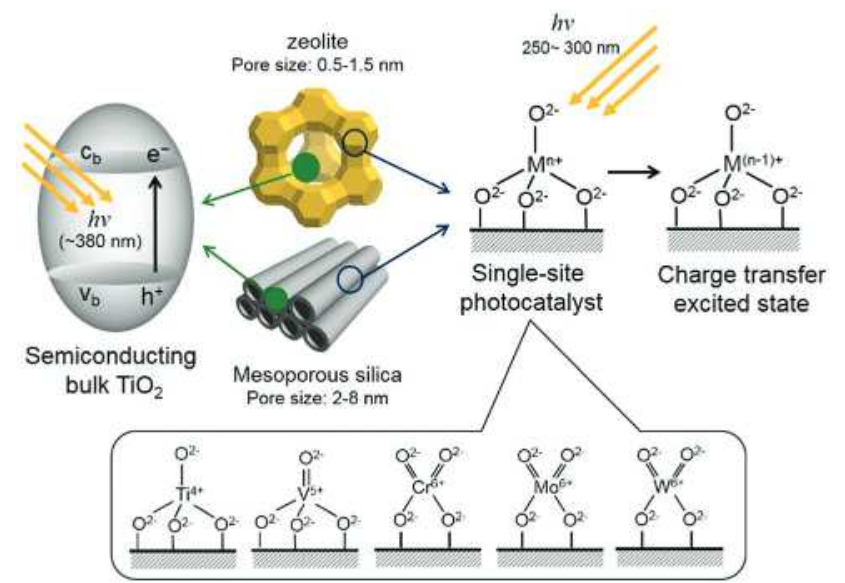

Fig. 2 Titanium oxide photocatalysts from semiconducting bulk $\mathrm{TiO}_{2}$ to isolated Ti-oxide molecular species implanted within silica matrices and the formation of a charge transfer excited state with tetrahedrally coordinated metal oxide moieties under UV-light irradiation. electron-hole pairs of trapped $\mathrm{h}$ centers and e centers that are localized in a quite short distance compared with the electrons and holes produced in semiconducting materials, exhibits unprecedented photocatalytic properties. The specific features of the single-site photocatalysts embedded in the silica matrices are reviewed in this section.

\subsection{Unique activity of single-site Ti-oxide photocatalysts}

Single-site Ti-oxide photocatalysts can be obtained by substituting $\mathrm{Si}$ atoms in silica matrixes with $\mathrm{Ti}$ atoms ( $\mathrm{Si} / \mathrm{Ti} 4$ 30), which are created by various anchoring techniques, such as hydrothermal synthesis, the sol-gel method, chemical vapor deposition, etc., and the isolated local structures of the single-site Ti-oxide moieties in a tetrahedral coordination geometry have been well evidenced from photoluminescence, ESR, and UV-vis spectra. ${ }^{25}$ In particular, the Ti K-edge XAFS measurement is an ideal technique to probe the chemical and structural environments of the titanium surroundings. ${ }^{26}$ Semiconducting bulk $\mathrm{TiO}_{2}$ gives rise to several well-defined preedge peaks attributable to the titanium in a symmetric octahedral en vironment, whereas the single-site Ti-oxide moiety exhibits an inten se single preedge peak at $4967 \mathrm{eV}$ corresponding to a dipole-allowed transition from the $1 \mathrm{~s}$ to $\mathrm{t} 2$ molecular levels built from the $3 \mathrm{~d}$ and $4 \mathrm{p}$ metal orbitals and from a neighbouring orbital. ${ }^{27}$

The TS-1 zeolite and the Ti-mesoporous silicas are active for the photocatalytic reduction of $\mathrm{CO}_{2}$ with $\mathrm{H}_{2} \mathrm{O}$, affording $\mathrm{CH}_{3} \mathrm{OH}$ and $\mathrm{CH}_{4}$ as the main products under UV-irradiation (Fig. 3). ${ }^{2,28-30}$ Ti-MCM-48 (pore size $42 \mathrm{~nm}$, 3-dimen sional channel) exhibits superior activity to TS-1 (B $0.6 \mathrm{~nm}, 3$-dimensional), Ti-MCM-41 (pore size $42 \mathrm{~nm}, 1$-dimensional) and semiconducting $\mathrm{TiO}_{2}$, which is presumably due to the combined contribution of the high dispersion state of the Ti-oxide moieties and the large pore size with a 3-dimensional channel structure of MCM-48. The single-site Ti-oxide moiety exhibits photoluminescence due to the radiative decay process from the charge transfer excited state of the Ti-oxide moieties in a tetrahedral coordination geometry,

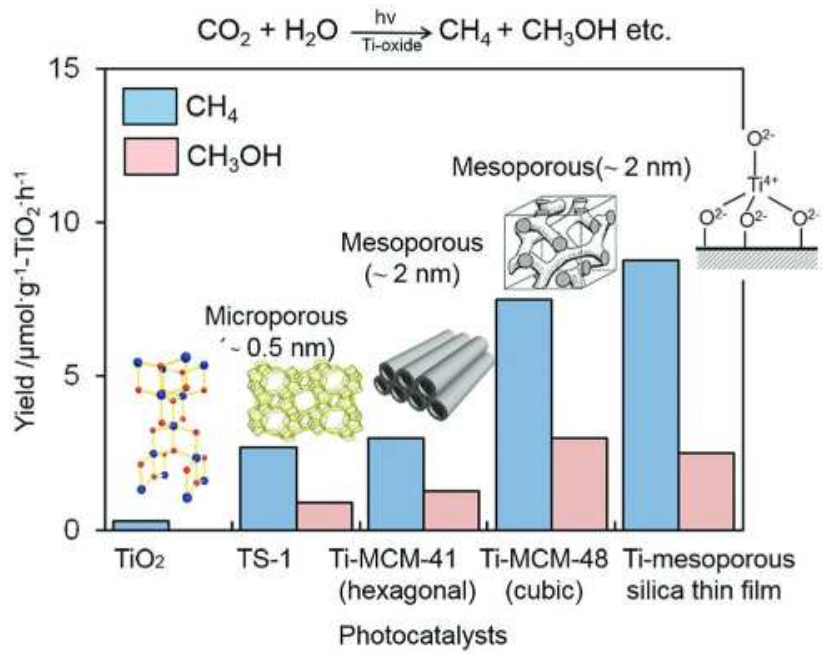

Fig. 3 The photocatalytic reduction of $\mathrm{CO}_{2}$ with $\mathrm{H}_{2} \mathrm{O}$ on various Ti- oxide photocatalysts. 
$\left(\mathrm{Ti}^{3+}-\mathrm{O}^{5}\right)^{2} *$, to their ground state upon excitation with light at around $250-280 \mathrm{~nm} .{ }^{31,32}$ The addition of $\mathrm{H}_{2} \mathrm{O}$ or $\mathrm{CO}_{2}$ molecules leads to the quenching of the photoluminescence, suggesting that $\mathrm{CO}_{2}$ or $\mathrm{H}_{2} \mathrm{O}$ interacts and/or reacts with the Ti-oxide species in both its ground and excited states.

The semiconducting $\mathrm{TiO}_{2}$ and the single-site Ti-oxide were found to lead to the evolution of $\mathrm{N}_{2}, \mathrm{O}_{2}$ and $\mathrm{N}_{2} \mathrm{O}$ with different selectivities in the presence of NO under UV-light irradiation. ${ }^{33,34}$ The single-site Ti-oxide moieties exhibited a high activity and selectivity for the predominant formation of $\mathrm{N}_{2}$, while $\mathrm{N}_{2} \mathrm{O}$ was the major product on the bulk $\mathrm{TiO}_{2}$ as well as on the catalysts with aggregated octahedrally coordinated Ti-oxide. The addition of NO on to the single-site Ti-oxide photocatalyst led to the appearance of a new ESR signal with a $g$ value of $\mathrm{g}_{>}=2.0015$ at $77 \mathrm{~K}$, attributed to the adsorbed NO species on the Ti ions. UV light irradiation of the catalyst led to a gradual linear decrease in the intensity of the ESR signal, which returned to its original level after UV light irradiation was discontinued. These changes in the ESR signal of the NO species suggest that not only do the adsorbed NO species act as reaction precursors but also the decomposition of NO proceeds photocatalytically.

\subsection{Visible-light sensitive single-site photocatalysts}

Single-site V, Cr, and Mo-oxide photocatalysts in a tetrahedral coordination geometry can operate as efficient photocatalysts for various reactions such as the photo-oxidation of hydrocarbons and the photoinduced metathesis of alkanes. ${ }^{35-37}$ In particular, the single-site Cr-oxide moieties implanted in mesoporous silica exhibit photocatalytic activities even under visiblelight irradiation. ${ }^{38,39}$ Upon excitation at around $450 \mathrm{~nm}$, the single-site Cr-oxide photocatalysts exhibit photoluminescence emission at around $550-750 \mathrm{~nm}$, which are attributed to the charge transfer processes on the tetrahedrally coordinated $\mathrm{Cr}$-oxide moieties having terminal $\mathrm{CrQ} \mathrm{O}$ as also evidenced by the XAFS and UV-vis measurements. In the case of the singlesite Cr-oxide moieties implanted in mesoporous silica (Cr-HMS), the fine structures due to the vibration mode of $\mathrm{CrQ} \mathrm{O}$ bonding can be observed, since the energy separation between the bands for the vibronic transition in the $\mathrm{Cr}$ O bond is more clear rather than the single-site Cr-oxide moieties implanted in a zeolite (CrS-1) (Fig. 4). This is presumably because the open space of the mesoporous structure is suitable to keep the isolated tetrahedrally coordinated structure without the perturbation due to the neighboring surface $\mathrm{OH}$ groups ${ }^{38}$ Based on such unique emission properties, Cr-HMS showed high photocatalytic activity for $\mathrm{NO}$ decomposition to produce $\mathrm{N}_{2}, \mathrm{~N}_{2} \mathrm{O}$ and $\mathrm{O}_{2}$ even under visible light irradiation ( $4450 \mathrm{~nm}$ ), while the reaction hardly occurred in the presence of CrS-1.

Moreover, it is possible to create binary metal oxide moieties, such as Cr,Ti-oxides and V,Ti-oxides, implanted within mesoporous silica frameworks using the photo-assisted deposition and metal ion-implantation methods. ${ }^{40}$ For example, the metal ion-implantation with $\mathrm{V}$ ions was effective in shifting the absorption band of the single-site Ti-oxide moieties to longer wavelengths, which enabled the photoepoxidation of propene
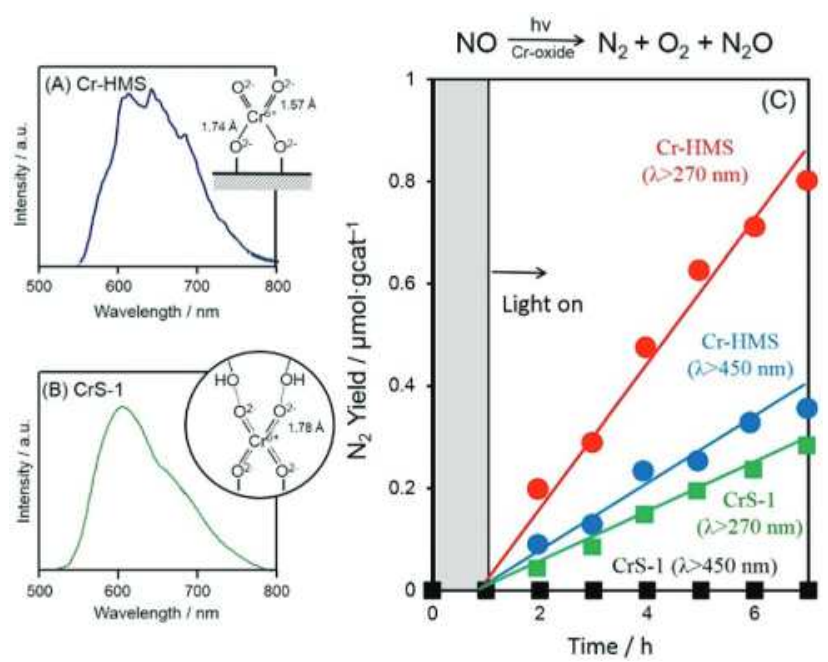

Fig. 4 Photoluminescence spectra of (A) Cr-HMS and (B) CrS-1, and (C) reaction time profiles in the photocatalytic $\mathrm{NO}$ decomposition on Cr-HMS and CrS- 1 under UV- light and visible light irradiation.

with molecular oxygen under visible light irradiation, while no reaction proceeded on the original single-site Ti-oxide.

\subsection{Application of single-site photocatalysts}

Single-site photocatalysts not only can promote photocatalytic reactions but can also be utilized to synthesize functional materials. A transparent mesoporous thin film with a singlesite photocatalyst generates the hydrophilic surface even before UV-light irradiation, and further superhydrophilic properties can be observed upon UV-light irradiation. ${ }^{41} \mathrm{We}$ have also demonstrated that the nano-sized metal and alloy nanoparticles can be photodeposited on the excited single-site photocatalyst under UV-light irradiation. ${ }^{42-44}$

As mentioned above, single-site photocatalysts with heteroatoms can generate potential active sites that exhibit the required activity and selectivity for specific reactions. However, the difficulties in recovering the small silica particles from the reaction mixture severely circumvent their industrial applications. To overcome these drawbacks, a multifunctional nanocomposite involving superparamagnetic NPs, ordered mesoporous channels, and isolated and tetrahedral Ti-oxide moieties has been developed, in which the magnetic cores are shielded by an impermeable coating and the Ti-oxide moieties are located on the external surface of the coating. ${ }^{45}$ As expected, recovery from the liquid reaction mixture was easily attained by applying an external permanent magnet, and the spent catalyst could be recycled.

A new type of core-shell structure catalyst that consisted of Pd NPs supported on a $\mathrm{SiO}_{2}$ core covered with a Ti-mesoporous shell was also developed in order to achieve one-pot oxidation reactions involving the synthesis of $\mathrm{H}_{2} \mathrm{O}_{2}$ from $\mathrm{H}_{2}$ and $\mathrm{O}_{2}$ gases by the Pd NPs and the subsequent oxidation reaction by the isolated Ti-oxide moiety using in situ produced $\mathrm{H}_{2} \mathrm{O}_{2} .{ }^{46}$ The optimized core-shell catalyst exhibited catalytic activity approximately 20 times higher than that of a conventional catalyst due 
to control of the Pd NP position, pore diameter, and thickness of the Ti-mesoporous shell by enhancement of the $\mathrm{H}_{2} \mathrm{O}_{2}$ utilization efficiency. ${ }^{47}$

\subsection{Metal ion photocatalysts}

Metal ions loaded onto the surface of silica or alumina easily aggregate, whereas the metal ions $\left(\mathrm{Cu}^{+}\left([\mathrm{Ar}] 3 \mathrm{~d}^{10}\right)\right.$ or $\left.\mathrm{Ag}^{+}\left([\mathrm{Kr}] 4 \mathrm{~d}^{10}\right)\right)$ immobilized in the zeolite pores by the ion exchange method are highly dispersed on the inner surfaces of the pores. The dispersion of the metal ions depends on the zeolite types, the $\mathrm{Si} / \mathrm{Al}$ ratio of the frameworks, the number and density of the ion exchange sites in the pores, the spatial volume of the pores, and the geometrical pore structure. A highly dispersed metal ion photocatalyst in an isolated state can be prepared in the pores of ZSM-5 or Mordenite zeolites having moderate density of ion exchange sites and pore diameters. ${ }^{48,49}$

$\mathrm{Cu}^{+}$and $\mathrm{Ag}^{+}$ions with the $\mathrm{d}^{10}$ state immobilized in zeolite pores can be excited to the $\left(\mathrm{d}^{9} \mathrm{~s}^{1}\right)$ electronic state by UV light irradiation, as shown in eqn (1) and (2) in Fig. 5. The s electrons and d vacancies generated by photoexcitation are considered as couples of excited electrons and holes, which are localized on one atom of $\mathrm{Cu}^{+}$and $\mathrm{Ag}^{+}$ions. This type of excited species can show unique photocatalytic activity different from a semiconductor photocatalyst. The dispersion and coordination structures of $\mathrm{Cu}^{+}$and $\mathrm{Ag}^{+}$ion species depend on pore shape/size and the ion exchange site density of pores, and their photocatalytic properties also change. For example, $\mathrm{Cu}^{+}$and $\mathrm{Ag}^{+}$ions immobilized in the ZSM-5 pores adopt a unique linear bidentate structure, which can show high photocatalytic performance for direct decomposition of nitrogen oxide (NOx) to $\mathrm{N}_{2}$ and $\mathrm{O}_{2}$ at room temperature. In particular, the $\mathrm{Ag}^{+}$ion photocatalyst can maintain photocatalytic activity even in the presence of oxygen and water and be applied as a catalyst for NOx decomposition and antibacterial remediation. The photocatalytic properties based on the formation of charge transfer excited species between inner shells have also been confirmed with rare earth ion $\mathrm{SP}^{3+}, \mathrm{Eu}^{3+}$, etc.) ion-exchanged in zeolite pores.

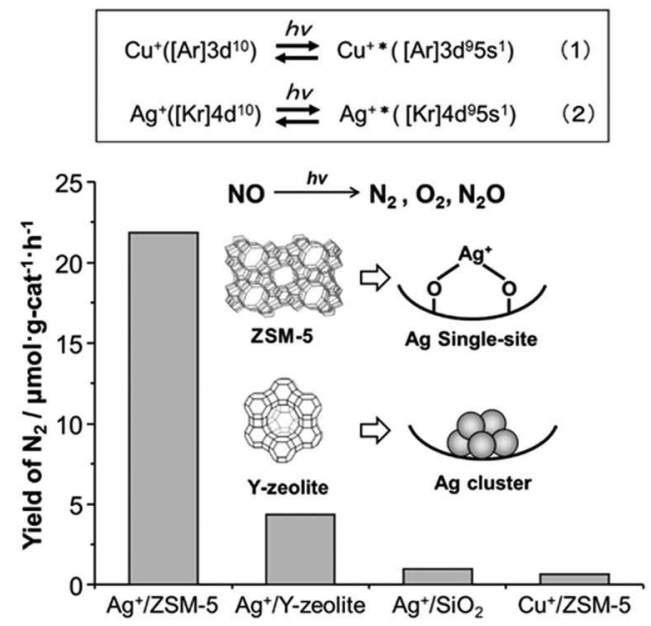

Fig. 5 Photocatalytic NO decomposition by $\mathrm{Ag}^{+}$and $\mathrm{Cu}^{+}$ion loaded photocatalysts.

\section{Visible-light-driven supported metal complexes on solid matrices}

Molecule-based photosystems in homogen eous solution s including emissive $\mathrm{d}^{6}$ or $\mathrm{d}^{8}$ metal complexes, such as $\mathrm{Ru}(\mathrm{II})$ and $\mathrm{Pt}(\mathrm{II})$, have been exten sively investigated in not only selective oxidation reactions but also $\mathrm{H}_{2}$ evolution from water, because of their precise controllability of the steric and electronic properties of metal centers by the appropriate choice of organic ligand based on molecular-engineering. ${ }^{50-53}$ The integration of such metal complexes with functional solid materials is the prominent strategy that bridges the gap between homogeneous and heterogen eous systems, ${ }^{3,54-57}$ which is also responsible for unpredicted physicochemical properties as single-site photocatalysts on the solid induced by not only steric- and electrostatic effects inside the constrained void spaces, but also the unique characteristics of the host materials.

Our design strategy employs encapsulation, anchoring, ionexchange, and intercalation techniques for the hybridization of metal complexes with rigid solid matrices, such as zeolites, mesoporous silica, organic polymers, and layered materials (Fig. 6). The use of solid matrices with special functional groups as promising macroligands for photocatalytically active centers has also led to the exploitation of unique catalytic functions, including isolation of well-defined active centers, cooperative catalysis by adjacent sites, and steric control of reaction intermediates. Thus, the solid matrices serve as promising macroligands for photocatalytically active single-atom centers.

\subsection{Encapsulation within the zeolite cavity}

Zeolites are promising host materials that can encapsulate a wide variety of organometallic complexes, ${ }^{58-60}$ in which the restricted pore structure often allows the stabilization of unstable reaction intermediates. Additionally, the electronic field and the volume of the space inside the zeolite supercage can be controlled by

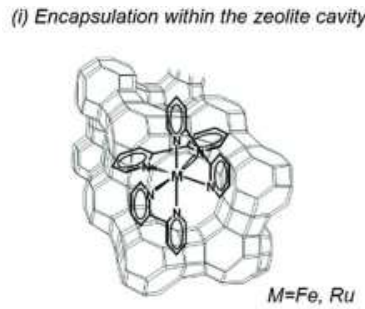

(ii) Anchoring within the mesoporous channel
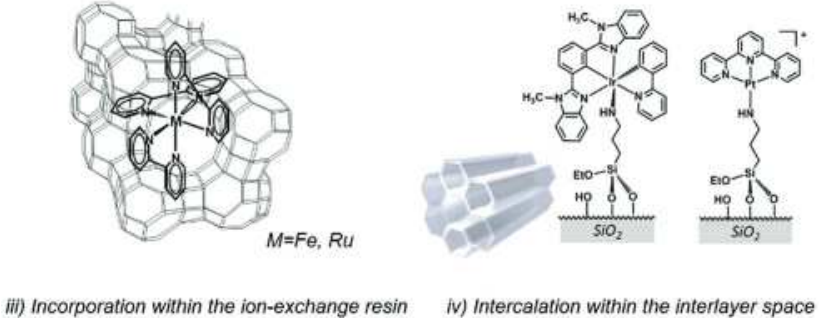

iii) Incorporation within the ion-exchange resin
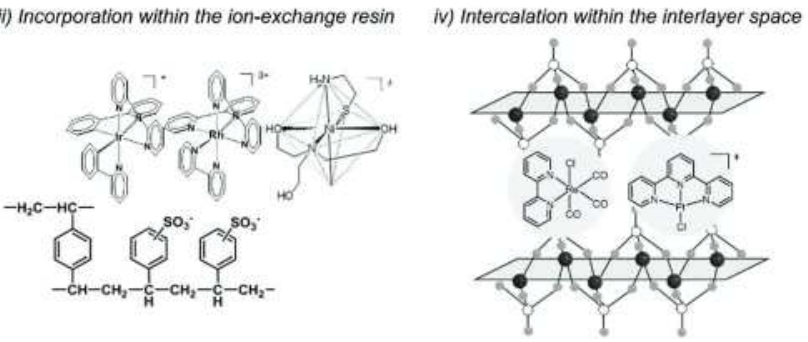

Fig. 6 Immobilization techniques of metal complexes on solid matrices. 
continuously varying the alkali metal cations from small $\mathrm{Li}^{+}$ to large $\mathrm{Cs}^{+}$.

In the case of zeolite $\mathrm{Y}$, which belongs to the faujasite family, the diameter of the supercage is $B 1.3 \mathrm{~nm}$, which enables the encapsulation of polybipyridyl complexes (B $1.2 \mathrm{~nm}$ ), but the direct exchange through the tunnels and/or windows with a widest diameter of B $0.74 \mathrm{~nm}$ cannot be realized. Thus the ship-in-a-bottle method is a strong protocol for the encapsulation of the complexes. ${ }^{61,62}$ The formation of the metal complexes within the supercage of zeolite $\mathrm{Y}$ was ascertained by an XRD pattern, in which the intensity of the (220) reflection was lower than that of (311). The encapsulation of $\mathrm{Fe}(\mathrm{bpy})_{3}{ }^{2+}$ in side zeolite $\mathrm{Y}$ cages allowed the aerobic oxidation of styrene derivatives under visible-light irradiation. It is interesting to note that the turnover number (TON) based on Fe atoms gradually improved using the larger size of the alkali metal cations. This tendency is corroborated with the increasing intensity of the metal-to-ligand charge transfer $\left({ }^{3} \mathrm{MLCT}\right)$ absorption of Fe(bpy $)_{3}{ }^{2+}$ and the decreasing electron density of the Fe centers, as determined using Fe K-edge XANES spectra. It should be noted that the inten sity of the phosphorescence emission due to the excited ${ }^{3} \mathrm{MLCT}$ state of $\mathrm{Ru}(\mathrm{bpy})_{3}{ }^{2+}$ complexes encapsulated within the supercage increased upon decreasing the size of the alkali metal cations. ${ }^{63}$ This result was found to correlate with the increased TON for the aerobic oxidation of styrene derivatives under visible-light irradiation. In the Stern-Volmer equation using $\mathrm{O}_{2}$ as a quencher, a larger quenching rate constant was obtained in the presence of lighter alkali metal cations. These results suggest that the zeolite cavity can control photocatalytic activities as well as emission properties related to the electronic configuration of the excited ${ }^{3} \mathrm{MLCT}$ state of the Ru(bpy) ${ }_{3}{ }^{2+}$ complex.

\subsection{Anchoring on to the silica surface}

The high surface areas and large pore volumes of mesoporous silica materials can facilitate the introduction of large size molecules, which cannot be included in the zeolite cavity, while retaining their well-defined active structure as well as high concentration. Their surfaces can also be readily tailored to afford specific characteristics by anchoring versatile silane coupling reagents with unique functional groups. ${ }^{64}$ The anchoring of the [Ir(Mebib)(ppy)Cl] (Mebib: bis(N-methylben zimidazolyl)pyridine, ppy: phenylpyridine) complex to mesoporous silica can be realized by the modification with (3-aminopropyl)triethoxysilane (APTES), via the formation of the new $\mathrm{Ir}-\mathrm{N}$ bond. The original $[\operatorname{Ir}(\mathrm{Mebib})(\mathrm{ppy}) \mathrm{Cl}]$ complex in acetonitrile solution showed a strong phosphorescence emission attributable to the ${ }^{3}$ MLCT transition at $77 \mathrm{~K}$, while the anchored Ir complex exhibited a high luminescence even at room temperature. ${ }^{65}$ Similarly, the anchored one enabled selective aerobic oxidation of transstilbene and 1-naphthol, while the reaction using the original homogeneous Ir precursor hardly occurred. It is assumed that the enhanced excitation rate and quantum efficiency of the anchored Ir complex, which originate from the reasonable suppression of the undesired deactivation processes inside the mesoporous channel, increase the energy-transfer from the excited ${ }^{3} \mathrm{MLCT}$ to $\mathrm{O}_{2}$, leading to an increase in photooxidation activity.
Additionally, the type of mesoporous silica structure also influences the photocatalytic activity, which increased in the order MCM-41 $\circ$ MCM-48 $\circ$ SBA-15. This tendency is well consistent with the larger quenching rate constant of SBA-15 in the SternVolmer equation using $\mathrm{O}_{2}$ as a quencher than those of MCM-48 and MCM-41. These results account for the larger pore diameter of SBA-15, which helps in the diffusion of $\mathrm{O}_{2}$ within the channels. Additionally, the 3D-connected channel structure of MCM-48 increases the diffusion efficiency compared to the unidirectional pore structure of MCM-41 with small diameter.

The anchoring of the $[\mathrm{Pt}(\mathrm{tpy}) \mathrm{Cl}]^{+}$(tpy: terpyridine) complex can also be attained by the same method using APTES modified mesoporous silica (Fig. 7). ${ }^{66-68}$ At low Pt loadings, the Pt complex is anchored without self-interaction and exhibits emission due to ${ }^{3}$ MLCT transitions at around $530 \mathrm{~nm}$. This isolated species is capable of promoting the photooxidation via energy and/or electron transfer from ${ }^{3} \mathrm{MLCT}$ to $\mathrm{O}_{2}$ to generate potentially active oxygen species. At high loading levels, the metalmetal-to-ligand charge-transfer ( ${ }^{3}$ MMLCT) transition at around $620 \mathrm{~nm}$ is prominent because of the short Pt teflert interactions with close proximity, which catalyze the $\mathrm{H}_{2}$-evolving reaction in aqueous media under visible-light irradiation. We succeeded in controlling the spatial distribution of the Pt complex in the mesoporous channel by varying the amount of Pt loading, which ultimately influences the phosphorescence emission and photocatalytic activities with predominant selectivities.

The $\mathrm{Ru}(\mathrm{bpy})_{3}{ }^{2+}$ species was anchored on to the surfaces of $\mathrm{Ag}$ NPs $\left(\mathrm{d}_{\mathrm{av}}=58 \mathrm{~nm}\right)$ coated with a sufficiently thin $\mathrm{SiO}_{2}$ layer (about $3 \mathrm{~nm}$ ), in order to demonstrate a new phenomenon that the excitation rate and quantum efficiency of the anchored $\mathrm{Ru}(\mathrm{bpy})_{3}{ }^{2+}$ were boosted by the local electromagnetic field near the plasmonic Ag NPs, which increases the energy and/or electron transfer from $\mathrm{Ru}(\mathrm{bpy})_{3}{ }^{2+}$ to $\mathrm{O}_{2}$, and ultimately enhances the photo-induced oxidation activity. ${ }^{69}$ Expectedly, the photoluminescence emission intensity under degassing conditions
(A)

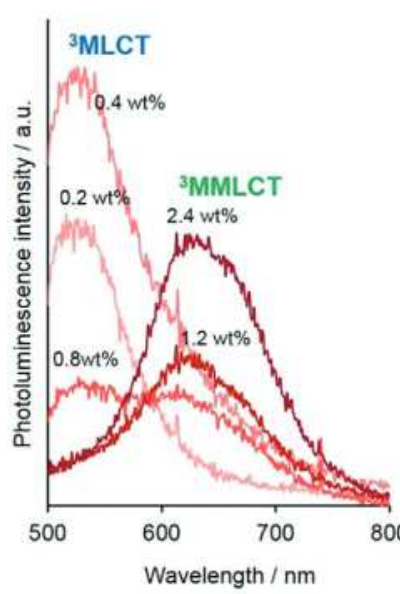

(B)

(C)

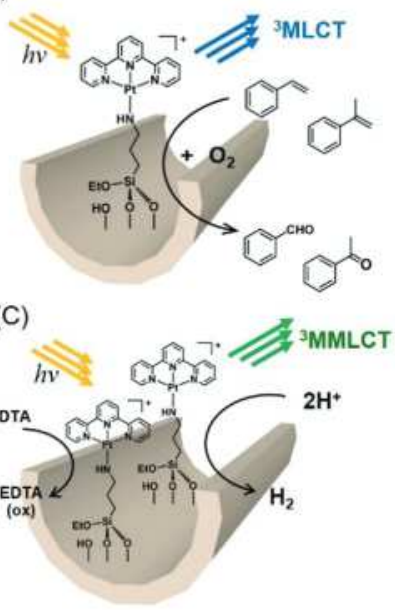

Fig. 7 (A) Photoluminescence spectra of Pt complex-anchored mesoporous silica MCM- 48 with various $\mathrm{Pt}$ loadings at room temperature $\left(\mathrm{l}_{\mathrm{ex}}=\right.$ $450 \mathrm{~nm}),(B)$ photocatalytic oxidation of styrene derivatives in the presence of $\mathrm{O}_{2}$ at low $\mathrm{Pt}$ loading, and $(\mathrm{C}) \mathrm{H}_{2}$ production from an aqueous solution. 
and photocatalytic activity using $\mathrm{O}_{2}$ were boosted with the assistance of LSPR, which are twice as large as those without the $\mathrm{Ag}$ core. The quantum yield attained by the $\mathrm{Ru}(\mathrm{bpy})_{3}{ }^{2+}$ species anchored onto the surface of $\mathrm{Ag} @ \mathrm{SiO}_{2}$ was determined to be $14 \%$, which is two times larger than that over the $\mathrm{Ru}(\mathrm{bpy})_{3}{ }^{2+}$ anchored onto the surface of colloidal $\mathrm{SiO}_{2}$ without the $\mathrm{Ag}$ core. The thin $\mathrm{SiO}_{2}$ shell not only provides chemical inertness and transparency toward visible light absorption, but also behaves as a spacer to optimize the LSPR effect. More significantly, the colloidal catalyst could be completely recovered without the leaching of active components and retained its original activity, demonstrating that the photooxidation proceeded on the $\mathrm{Ru}$ complex on the $\mathrm{Ag} @ \mathrm{SiO}_{2}$ surface, but not with the detached one.

\subsection{Incorporation within the macroreticular resin}

The unique characteristics inside the macroreticular domains of the organic polymers, including moderate surface areas, and acidic/basic and hydrophilic/hydrophobic properties, are very attractive for the design of heterogeneous catalysts. It is further expected that the introduction of appropriate surface functional groups in the vicinity of catalytically active cen ters exerts a beneficial impact on their performances. ${ }^{70}$

Direct ion-exchange of bis-(2-phenylpyridine)-(2,20-bipyridine)iridium(III) $\left(\left[\operatorname{Ir}(\mathrm{ppy})_{2}(\mathrm{bpy})\right]^{+}\right)$as a photosensitizer and $\left[\mathrm{Rh}(\mathrm{bpy})_{3}\right]^{3+}$ as a $\mathrm{H}_{2}$ evolution catalyst has been accomplished with an acidic polymer possessing $-\mathrm{SO}_{3}{ }^{\text {}}$ groups. ${ }^{71}$ Aphotoluminescence quenching experiment evidenced that both complexes are located in a short separation and the occurrence of electron transfer from $\mathrm{Ir}$ to $\mathrm{Rh}$, which enabled $\mathrm{H}_{2}$ evolution as a heterogen eous catalyst under visible-light irradiation in the absence of an electron mediator.

Numerous uses of precious metals, such as Pt, Rh, and Ir, have evoked widespread interest in the possibility for the use of abundant and inexpensive metal complexes consisting of $\mathrm{Fe}$, $\mathrm{Co}$, and Ni. ${ }^{72}$ The introduction of $\mathrm{Ni}\left(\mathrm{NiL}_{2}\right)_{2} \mathrm{Cl}_{2}(\mathrm{~L}=$ b-mercaptoethylamine) into an acidic polymer possessing $-\mathrm{SO}_{3}{ }^{\text {[I }}$ groups creates a monomeric $\mathrm{Ni}$ species in octahedral coordination ligated by a mercaptoethylamine and $\mathrm{H}_{2} \mathrm{O}$, which further transformed in to a real catalytically active $\mathrm{Ni}$ (II) species surrounded by b-mercaptoethylamine and triethanol amine (TEOA) ligands during the induction period of the $\mathrm{H}_{2}$ production under visible-light irradiation using Eosin $\mathrm{Y}$ as a photosensitizer and TEOA as a sacrificial reagent. ${ }^{73}$ It should be noted that the catalytic activity was superior to that of the homogeneous precursor by a factor of 5 , because the functional polymer matrix offers a unique reaction field that allows the reasonable transformation of the active center, which cannot be attained by the homogen eous counterparts.

\subsection{Intercalation within the interlayer space of layered} materials

The utilization of the two dimensional interlayer space of inorganic layered materials with structurally rigid and well-defined arrangements is another strategy to construct organic-inorganic hybrid materials via the intercalation of metal complexes.
$\mathrm{K}_{4} \mathrm{Nb}_{6} \mathrm{O}_{17}$ is accepted as one of the essential classes of layered materials, in which $\mathrm{K}^{+}$ions with in the interlayer space between two anionic sheets are exchangeable with methyl viologen, ${ }^{74}$ porphyrin, ${ }^{75}$ and $\left[\mathrm{Ru}(\mathrm{bpy})_{3}\right]^{2+} \cdot{ }^{26}$ Unlike the free Pt complex in solution, the intercalation of $[\mathrm{Pt}(\mathrm{tpy}) \mathrm{Cl}]^{+}$exhibits strong emission from an excited ${ }^{3}$ MMLCT state originating from short

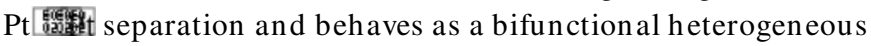
photocatalyst enabling visible-light sensitization as well as $\mathrm{H}_{2}$ evolution from water in a single-component with high reusability. ${ }^{77}$ The intercalation of two components, visible-light responsive $\operatorname{Ir}(\mathrm{III})$ and proton reduction catalyst $\mathrm{Rh}$ (III) complexes, also succeeded in affording a new type of heterogeneous photocatalyst whose activity was higher than those of the homogeneous counterparts by a factor of about $2 .^{78}$

Zirconium phosphate $\left(\mathrm{Zr}\left(\mathrm{HPO}_{4}\right)_{2} \mathrm{H}_{2} \mathrm{O}, \mathrm{a}-\mathrm{ZrP}\right)$ also allows intercalation via the strong electrostatic interaction between the exchangeable proton and the guest molecules with positive charge. The visible-light-driven photocatalytic $\mathrm{CO}_{2}$ conversion system was constructed by the intercalation of $\operatorname{Re}(\mathrm{bpy})(\mathrm{CO})_{3} \mathrm{Cl}$ combined with Rhodamine $\mathrm{B}(\mathrm{RhB})$ as a photosensitizer and TEOA as a sacrificial reagent. ${ }^{79}$ Additionally, this hybrid catalyst showed outstanding durability and was recycled several times without any loss of activity, presumably because of the trapping of the unstable Re complex within the restricted interlayer space. Moreover, leaching and agglomeration of the active metal species were not observed for all photocatalytic systems, and the recovered photocatalyst can be reused without significant deterioration in their catalytic activity.

\section{4. $\mathrm{TiO}_{2}$ - Loaded porous silicate materials}

Since the discovery by Honda and Fujishima, titanium dioxide $\left(\mathrm{TiO}_{2}\right)$ has extensively been investigated as a promising photocatalyst capable of decomposing organic compounds in to $\mathrm{CO}_{2}$ and $\mathrm{H}_{2} \mathrm{O}$ under en vironmentally-benign conditions using ultraviolet (UV) light as an energy source. ${ }^{7,80}$ Owing to its inherent chemical stability, suitable band gap energy for photo-induced redox reactions, low cost for production, and low toxicity, the photocatalysis of $\mathrm{TiO}_{2}$ has been regarded as a key technology to solve environmental problems, including water/air purification, sterilization, antibacterial coating and antifouling, while applications in solar energy conversion, energy storage and green chemical synthesis have been attracting tremendous attention as well. ${ }^{81}$

The heterogeneous photocatalysis of $\mathrm{TiO}_{2}$ provides multiple chemical events on its surface $;^{82,83}$ under UV light irradiation, the wettability of a $\mathrm{TiO}_{2}$ surface drastically changes, which is responsible for the photo-induced self-cleaning effect of $\mathrm{TiO}_{2}$. The photo-excited electrons and holes in $\mathrm{TiO}_{2}$ react with the surrounding $\mathrm{O}_{2}$ and $\mathrm{H}_{2} \mathrm{O}$ molecules on its surface to produce superoxide anions $\left({ }^{W_{2}}{ }_{2}\right)$ and hydroxyl radicals $\left({ }^{5} \mathrm{OH}\right)$, respectively. These radical species can react with the surrounding organic reactants to completely mineralize them in to $\mathrm{CO}_{2}$ and $\mathrm{H}_{2} \mathrm{O}$. Practical en gineering applications of $\mathrm{TiO}_{2}$ photocatalysts 
require fixation on inorganic support materials or blending with binder materials to facilitate the catalyst recovery. Previous studies have reported on $\mathrm{TiO}_{2}$ photocatalytic systems supported using mechanically and chemically stable oxides, including silica and alumina, ${ }^{84}$ and sorbents such as clays as support materials. ${ }^{85}$ However, the resulting photocatalytic activities have been commonly reported to be less active than the corresponding $\mathrm{TiO}_{2}$ alone, because the combination with support materials often leads to a reduced crystallinity of $\mathrm{TiO}_{2}$ particles. According to previous research studies, we have found that the utilization of porous silicate materials as supports for $\mathrm{TiO}_{2}$ photocatalysts can create more efficient photo-catalytic systems. ${ }^{4,86}$ Porous silicate materials with interesting and tunable nano-architectures periodically aligned in the nanoscale can offer large surface areas, adsorption and condensation properties towards guest molecules, and transparency to UV and visible light, which can serve as suitable nano-reactors for the design of heterogeneous photocatalytic systems. We have recently designed various types of $\mathrm{TiO}_{2}$-loaded porous silicate materials with diverse surface functionalities, which not only facilitate the recovery of catalysts but also improve the photocatalytic efficiency of $\mathrm{TiO}_{2}$ due to their enhanced adsorption properties towards organic compounds diluted in water and air. The following section summarizes our recent findings on the utilization of porous silicate materials as supports in the development of high performance $\mathrm{TiO}_{2}$-based photocatalysts.

\section{1. $\mathrm{TiO}_{2}-$ Zeolite composite photocatalysts}

Zeolites are microporous aluminosilicate materials formed by the crosslinkage of $\mathrm{SiO}_{4}{ }^{4[\mathrm{En}}$ and $\mathrm{AlO}_{4}{ }^{5[\mathrm{EV}}$ tetrahedral units. The general formula is expressed as $\mathrm{M}_{\mathrm{m}}\left[\mathrm{Al}_{\mathrm{m}} \mathrm{Si}_{\mathrm{n}} \mathrm{O}_{2(\mathrm{~m}+\mathrm{n})}\right] \mathrm{E}_{\mathrm{a}} \mathrm{H}_{2} \mathrm{O}$, where $\mathrm{M}$ is an exchangeable cation $\left(\mathrm{H}^{+}, \mathrm{Na}^{+}, \mathrm{K}^{+}, \mathrm{Ca}^{2+}, \mathrm{Mg}^{2+}\right.$, etc.) electrostatically trapped at the tetrahedral aluminium sites in the extra framework for charge compensation. Large surface areas derived from the micropore channel systems as well as the electrostatically polarized cation-exchange sites are responsible for the strong adsorption properties of zeolites toward small organic reactants. In a primitive study, we examined the photocatalytic activities of $\mathrm{TiO}_{2}$-zeolite composites in the photocatalytic degradation of 2-propanol diluted in water under UV light irradiation (Fig. 8).

Various types of zeolites accommodating $10 \mathrm{wt} \%$ of $\mathrm{TiO}_{2}$ particles were prepared by the conventional wet impregnation method using titanium ammonium oxalate $\left(\left(\mathrm{NH}_{4}\right)_{2}\left[\mathrm{TiO}\left(\mathrm{C}_{2} \mathrm{O}_{4}\right)_{2}\right]\right)$ dissolved in water as a titanium precursor, followed bycalcination at $550 \mathrm{IC}$ in air. The photocatalytic activities (normalized by the mass of $\mathrm{TiO}_{2}$ in the catalyst) were found to be highly dependent on the $\mathrm{SiO}_{2} / \mathrm{Al}_{2} \mathrm{O}_{3}$ ratio of the zeolite framework, while their topologies and surface areas did not provide any clear correlations. ${ }^{86}$ In particular, $\mathrm{TiO}_{2}$ particles supported on high-silica zeolites, such as HY(200) and ZSM-5(760), showed superior photocatalytic activities to $\mathrm{TiO}_{2}$ alone or $\mathrm{TiO}_{2}$ particles supported on conventional oxide supports. The observed activity trend was found to be associated with the adsorption behavior of water molecules; Al-rich zeolites having inherently high water adsorption capacities, such as $\mathrm{NaA}(2.1), \mathrm{NaY}(2.5)$ and $\mathrm{HY}(5.0)$,

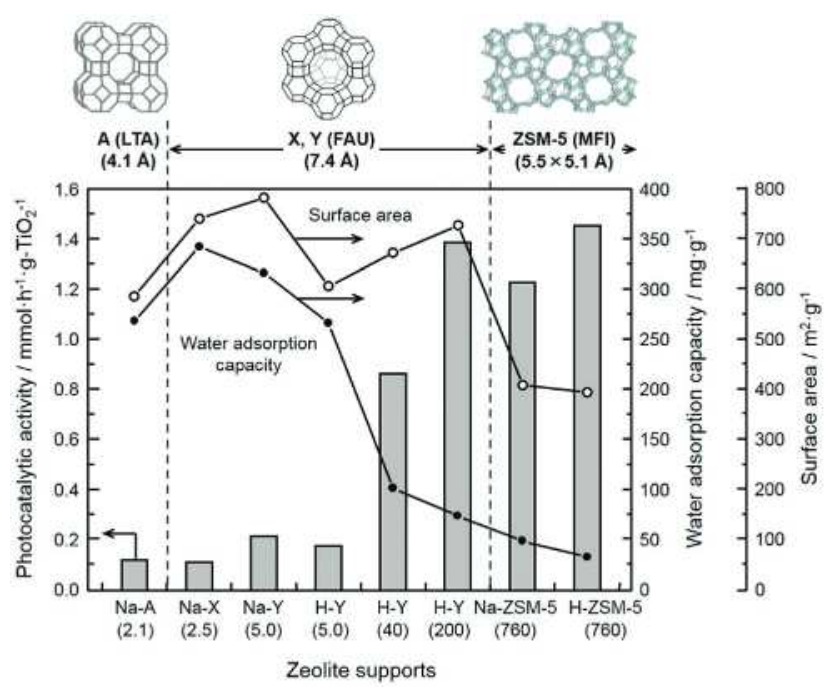

Fig. 8 Comparison of the photocatalytic activities of $\mathrm{TiO}_{2}$ photocatalysts supported on various types of zeolites and their water adsorption capacities and surface areas. The photocatalytic activities were determined by the photocatalytic degradation of 2-propanol diluted in water under UVlight irradiation. Reproduced from ref. 86 with permission from The Royal Society of Chemistry.

exhibited lower photocatalytic activities, while high-silica zeolites with lower water adsorption capacities, such as HY(40), HY(200) and ZSM-5(760), commonly provided higher photocatalytic activities. This result demonstrates that the hydrophobicity of the zeolite surface dominates the photocatalytic activity in such $\mathrm{TiO}_{2}$-zeolite composite photocatalytic systems working in an aqueous medium, rather than other structural factors. Since water is a highly polarized molecule, an Al-rich hydrophilic surface allows a preferential adsorption of water, which interrupts the adsorption of organic reactants, hence resulting in a decreased catalytic activity. On the other hand, a Si-rich hydrophobic surface allows an adsorption of organic reactants, facilitates the transportation to active $\mathrm{TiO}_{2}$ sites, and thus leads to an effective photocatalytic degradation.

4.1.1. Dealumination of zeolite supports. Dealumination is one of the widely-accepted techniques to improve the surface hydrophobicity of a zeolite, by which the Al atoms are expelled from the zeolite framework, while the framework structure remains unchanged. A highly hydrophobic FAU zeolite was prepared without any significant loss of crystallinity and sorption capacity by an easy two-step preparation method, which consists of predealumination treatment using strong protonic acids (e.g. $\mathrm{HNO}_{3}, \mathrm{HCl}$ ) and the subsequent calcination treatment at elevated temperature $(\mathrm{B} 1000 \mathrm{1C}){ }^{87}$ The thermogravimetric, IR, and ${ }^{29} \mathrm{Si} \mathrm{NMR}$ analyses confirmed that the high hydrophobicity of the Y-zeolite can be achieved by the postsynthetic dealumination treatment due to the formation of a refined silica surface having fewer $\mathrm{Al}$ and silanol sites. As expected, when the thus-prepared hydrophobic Y zeolite was utilized as a support for $\mathrm{TiO}_{2}$, the photocatalytic degradation rates were significantly improved both in aqueous- and in gaseous phase reactions because of its improved hydrophobic nature. Such a $\mathrm{TiO}_{2}$-loaded 
hydrophobic zeolite photocatalyst was further extendable to the selective oxidation of olefins in an organic medium. We demonstrated that $\mathrm{TiO}_{2}$ confined in a hydrophobic zeolite could afford a higher catalytic activity in the epoxidation of olefins in the presence of molecular $\mathrm{O}_{2}$ as an oxidant under UV light, and outperforms $\mathrm{TiO}_{2}$ confined in untreated hydrophilic zeolites. ${ }^{88}$

4.1.2. Effect of Ti precursors. In the design of $\mathrm{TiO}_{2}$-zeolite composite photocatalysts, the Ti precursor also strongly affects the characteristics of a $\mathrm{TiO}_{2}$ photocatalyst in terms of its crystallinity and light absorption properties, which play important roles in determining the final photocatalytic activity. For instance, two different $\mathrm{TiO}_{2}$ precursors, titanium ammonium oxalate $\left(\mathrm{AO}:\left(\mathrm{NH}_{4}\right)_{2}\left[\mathrm{TiO}\left(\mathrm{C}_{2} \mathrm{O}_{4}\right)_{2}\right]\right)$ and ammonium hexafluorotitanate $\left(\mathrm{AF}:\left(\mathrm{NH}_{4}\right)_{2}\left[\mathrm{TiF}_{6}\right]\right)$, show clear differences. ${ }^{89,90} \mathrm{TiO}_{2}$ photocatalysts supported on a commercially available hydrophobic Y-zeolite $\left(\mathrm{SiO}_{2} / \mathrm{Al}_{2} \mathrm{O}_{3}=810\right)$ were prepared using these $\mathrm{Ti}$ precursors (denoted $\mathrm{AO}-\mathrm{TiO}_{2} / \mathrm{Y}$ and $\mathrm{AF}-\mathrm{TiO}_{2} / \mathrm{Y}$, respectively). Hydrofluoric acid gas evolved during the thermal decomposition of $\mathrm{AF}$ to $\mathrm{TiO}_{2}$ in air can react with the surface hydroxyl groups on the Y-zeolite, which leads to the formation of fluorinated groups. FT-IR investigations clearly show the decreases of the surface hydroxyl group den sity on the Y-zeolite. The amount of water adsorbed on $\mathrm{AF}-\mathrm{TiO}_{2} / \mathrm{Y}$ was one-third less than that on $\mathrm{AO}-\mathrm{TiO}_{2} / \mathrm{Y}$ in a low relative pressure region $\left(\mathrm{P} / \mathrm{P}_{0} \mathrm{~A} \quad 0.2\right)$ in the water adsorption isotherm, indicating a more hydrophobic nature of the $\mathrm{AF}-\mathrm{TiO}_{2} / \mathrm{Y}$ surface. Furthermore, $\mathrm{AF}-\mathrm{TiO}_{2} / \mathrm{Y}$ shows visible light absorption in the region from 400 to $500 \mathrm{~nm}$, thus giving a yellow coloration, whereas $\mathrm{AO}-\mathrm{TiO}_{2} / \mathrm{Y}$ is a simple white powder, indicating that nitrogen and fluorine atoms derived from $\mathrm{AF}$ are doped into $\mathrm{TiO}_{2}$ crystals during the thermal decomposition, thus extending the light absorption to the visible light region. With these improved functionalities, $\mathrm{AF}^{-}-\mathrm{TiO}_{2} / \mathrm{Y}$ showed a superior photocatalytic performance to $\mathrm{AO}-\mathrm{TiO}_{2} / \mathrm{Y}$ in the degradation of 2-propanol as a model contaminant in water and air under both UV and visible light ( $4420 \mathrm{~nm}$ ) irradiation conditions, in which a good relationship was observed between the adsorption capacities toward 2-propanol and the observed photocatalytic activities. Thus, the fluorine-containing Ti precursor was found to be effective in enhancing the photocatalytic characteristics of the $\mathrm{TiO}_{2}$-zeolite composite.

\section{2. $\mathrm{TiO}_{2}-$ Mesoporous silica composite photocatalysts}

The channel size of zeolites is intrinsically narrow (less than $2 \mathrm{~nm}$ ); therefore, the adsorption and mass transfer of large organic compounds within zeolite crystals are significantly limited. Mesoporous silicas having meso-size pores with 2-50 nm size can provide more extended catalytic opportunities as host materials. A number of research studies have been reported on the post-modification of mesoporous silica to improve the hydrophobicity of its surface. The overwhelming majority of the methods is the surface modification using organosilane coupling agents containing hydrophobic alkane functional groups (e.g. methyl, propyl, octyl, phenyl, etc.). For example, Inumaru et al. demonstrated that the n-octyl-grafted $\mathrm{TiO}_{2} / \mathrm{MCM}-41$ decomposed 4-nonylphenol polyethoxylate (NEPO), an endocrine disrupter, diluted in water under UV light irradiation, and outperformed commercial $\mathrm{TiO}_{2}$ under identical reaction conditions. ${ }^{91}$ The improved photocatalytic activity was attributed to the hydrophobic nano-spaces, which enabled selective adsorption/ condensation of low-concentration NEPO molecules from water. Thus, the adsorption and enrichment of organic pollutants on the catalyst surface play critical roles in achieving a high catalytic efficiency.

Surface-chemistry engineering to improve the adsorption/ enrichment of organic pollutants on the catalyst surface is key to constructing efficient $\mathrm{TiO}_{2} /$ mesoporous silica photocatalytic systems (Fig. 9). ${ }^{92}$ To this end, we developed an alternative method to modify a silica surface using a fluorine-containing silane coupling agent, trieth oxyfluorosilane (TEFS) ${ }^{93,94}$ Fig. 10(A) schematically illustrates the surface modification of a $\mathrm{TiO}_{2} /$ mesoporous silica photocatalyst with TEFS, in which the thermally stable $\mathrm{Si}-\mathrm{F}$ bond is covalently anchored on the silica surface. Grafting an optimal amount of TEFS onto HMS-type mesoporous silica (pore diameter of B 2-3 nm) was found to be effective in dramatically decreasing the water adsorption capacity, by reducing the silanol group density on the silica surface, without any significant loss of the original porous structure (Fig. 10(B)). With UV light irradiation, $\mathrm{TiO}_{2}$ on TEFS-modified HMS (named $\mathrm{TiO}_{2} /$ FS-HMS) exhibited a dramatically improved adsorption ability and photocatalytic activity toward some organic pollutants (e.g. 2-propanol, phenol) diluted in water compared to that supported on pristine HMS silica (Fig. 10(C)). The obtained catalytic activity exceeded that of commercial $\mathrm{TiO}_{2}$ photocatalyst powder (Evonik, P25 $5^{\mathrm{s}}$ ) under the same reaction conditions. The photocatalytic activities corresponded well to the adsorbed amounts of organic molecules, evidencing that the hydrophobic nature of the silica support plays a critical role in determining the final photocatalytic degradation rate, i.e. hydrophobic pores with less affinity with water molecules allow adsorption of organic reactants and give them easy access to the $\mathrm{TiO}_{2}$ active sites, resulting in a higher photocatalytic efficiency.

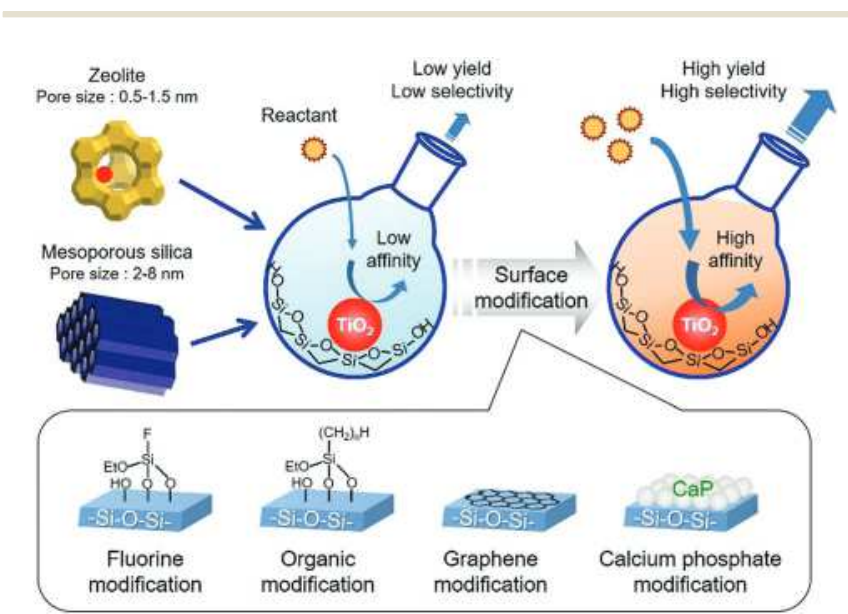

Fig. 9 Schematic illustration of the surface-chemistry engineering of the $\mathrm{TiO}_{2} /$ silica composite photocatalyst. 
(A)

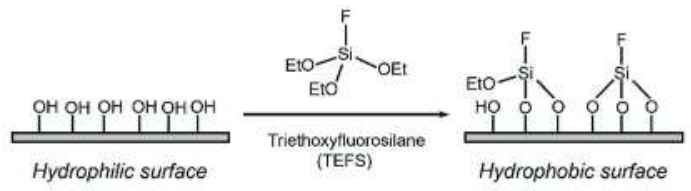

(B)

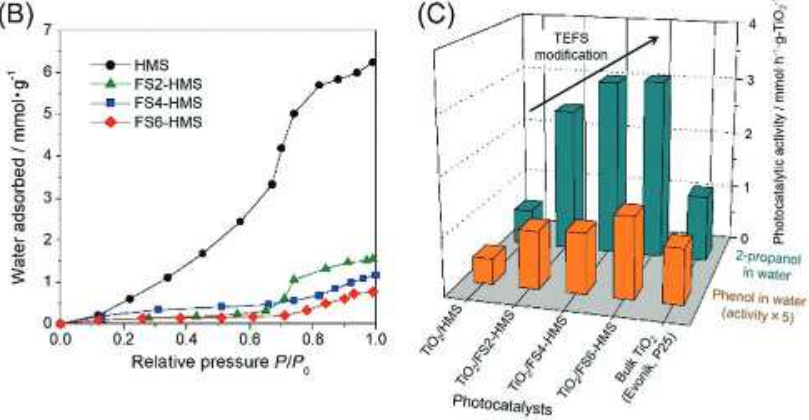

Fig. 10 (A) Schematic illustration of the surface modification of a silica surface with triethoxyfluorosilane (TEFS) as a silylation agent. (B) Water adsorption isotherms of TEFS modified HMS silicas measured at $251 \mathrm{C}$. (C) Comparison of the photocatalytic activities of $\mathrm{TiO}_{2}$ photocatalysts supported on TEFS modified HMS silicas and commercial $\mathrm{TiO}_{2}$ (Evonik, $\mathrm{P}^{5} 5^{\mathrm{s}}$ ) in the photocatalytic degradation of 2-propanol in water $\left(2.6 \mathrm{mmol}^{\mathrm{L}}\right)$ and phenol diluted in water $\left(0.23 \mathrm{mmol}^{[\mathrm{WI}}\right)$ under UV-light irradiation. Adapted from ref. 94 with permission from American Chemical Society.

\section{3. $\mathrm{TiO}_{2}$ photocatalysts supported on CaP-modified silica}

We also developed an alternative surface-engineering method of mesoporous silica in order to construct a photocatalytic degradation system effective for the specific target organic compounds in water. Calcium phosphate $(\mathrm{CaP})$ mineral was chosen as a modifier, since cationic $\mathrm{Ca}^{2+}$ ions and anionic $\mathrm{PO}_{4}{ }^{3 \%}$ ions are expected to provide strong interactions between specific organic molecules, and calcium phosphates, exemplified by hydroxyapatite $\left(\mathrm{Ca}_{10}\left(\mathrm{PO}_{4}\right)_{6}(\mathrm{OH})_{2}\right)$, are known to show strong affinity toward protein molecules. ${ }^{95-97}$ Incorporation of $\mathrm{CaP}$ into a $\mathrm{TiO}_{2}$-loaded $\mathrm{SBA}-15$ silica $\left(\mathrm{TiO}_{2} / \mathrm{SBA}-15\right)$ surface was achieved by a facile sol-gel process, in which ethanolic solution s containing calcium nitrate tetrahydrate $\left(\mathrm{Ca}\left(\mathrm{NO}_{3}\right)_{2}{ }_{2}{ }_{4} \mathrm{H}_{2} \mathrm{O}\right)$ and phosphoric pentoxide $\left(\mathrm{P}_{2} \mathrm{O}_{5}\right)$ were used as $\mathrm{Ca}$ and $\mathrm{P}$ precursors, respectively, and the $\mathrm{Ca} / \mathrm{P}$ molar ratio was adjusted to B $1.67 .{ }^{98}$ TEM showed mesopore channels typical of SBA-15, which were clearly observed over a large domain, and no aggregated particles were present after $\mathrm{CaP}$ modification, indicating that the SBA-15 silica surface was uniformly covered by CaP. The absorption capacities and photocatalytic activities of the samples were examined using methylene blue (MB), a cationic dye molecule often found in textile synthetic wastewater, as a model contaminant in water. An increased MB uptake was achieved on a CaP-modified $\mathrm{TiO}_{2} / \mathrm{SBA}-15$ composite after the modification of SBA-15 silica with CaP (Fig. 11(A)), suggesting that $\mathrm{MB}$ with positively charged nitrogen-alkyl groups could be easily enriched on the surface of CaP-SBA-15 with abundant $\mathrm{PO}_{4}{ }^{3 \text { 泫 }}$ groups through electrostatic interactions. Under UV light irradiation, CaP-modified $\mathrm{TiO}_{2} / \mathrm{SBA}-15$ exhibited an improved photocatalytic performance in the degradation of $\mathrm{MB}$ compared with the unmodified analogue. A moderate adsorption
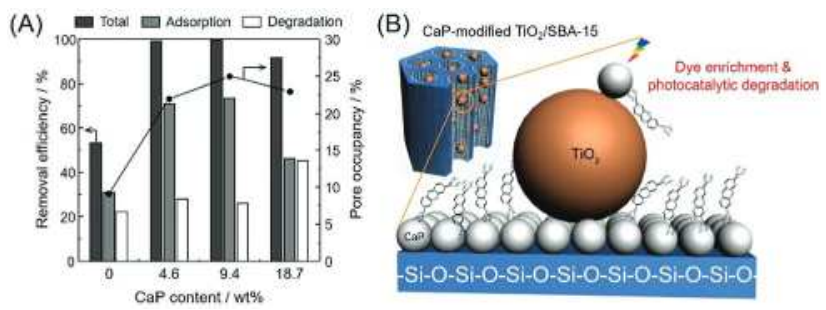

Fig. 11 (A) Removal efficiency of MB by adsorption, photocatalytic degradation, and sum of them (total) on $\mathrm{TiO}_{2} / \mathrm{SBA}-15$ hybrid photocatalysts modified with different amounts of $\mathrm{CaP}(0-18.7 \mathrm{wt} \%)$ and (B) schematic illustration of the adsorption and photocatalytic degradation kinetics of $\mathrm{MB}$ dye on $\mathrm{CaP}$-coated $\mathrm{TiO}_{2} / \mathrm{SBA}-15$. Adapted from ref. 98 with permission from American Chemical Society.

affinity toward MS allows adsorption/diffusion of MB in the mesopore spaces of SBA-15, leading to the enrichment of MB around the $\mathrm{TiO}_{2}$ particles. This close proximity between the reactants and photocatalytically active sites is likely key to improving the photocatalytic degradation efficiency (Fig. 11(B)).

\subsection{Carbon coating of $\mathrm{TiO}_{2}$ photocatalysts supported on} mesoporous silica

We also carried out the selective and direct modification of a $\mathrm{TiO}_{2}$ surface loaded onto MCM-41 mesoporous silica $\left(\mathrm{TiO}_{2} / \mathrm{MCM}-41\right)$ by graphene synthesis. Carbon materials often exhibit hydrophobicity and show good affinity toward organic molecules. ${ }^{99-101}$ In recent years, nanostructured carbon materials (e.g. carbon nanotubes, graphene) have been widely investigated due to their unique functions. In this case, we modified the surface of $\mathrm{TiO}_{2}$ with graphene, via the formation of surface complexes between $\mathrm{TiO}_{2}$ and 2,3-dihydroxynaphthalene (DN) followed by carbonization in an inert gas atmosphere (Fig. 12(A)), utilizing the specific reaction between the $\mathrm{TiO}_{2}$ surface and the hydroxyl groups of aromatic molecules (e.g. phenol, catechol and salicylic acid). This dehydration reaction selectively occurs on the surface of $\mathrm{TiO}_{2}$, enabling the selective coating of the $\mathrm{TiO}_{2}$ surface with graphene. ${ }^{102-105}$ A clear color change was observed after the formation of a surface complex, and the successive carbonization under an in ert atmosphere at relatively high temperature caused a
(A)

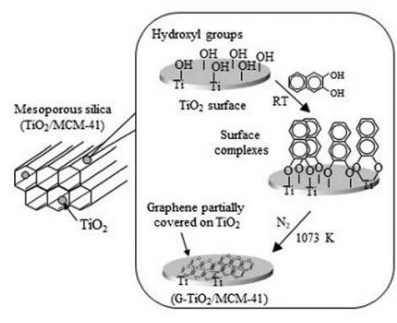

(B)

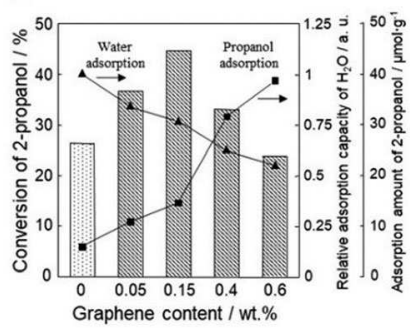

Fig. 12 (A) Schematic diagram of the procedures in the selective graphene modification of the $\mathrm{TiO}_{2}$ surface supported on MCM-41 and (B) effect of the contents of graphene on the photocatalytic activities for the degradation of 2-propanol (reaction time: $6 \mathrm{~h}$ ), and water and 2-propanol adsorption capacities. Reproduced from ref. 106 with permission from American Chemical Society. 
successful transformation in to graphene, which was confirmed by Raman spectroscopy. ${ }^{106}$ As the graphene content in the samples increased, a decrease in the water adsorption capacity was observed, and accordingly an increase in the 2-propanol adsorption capacity was observed, demonstrating an improved surface hydrophobicity by graphene modification (Fig. 12(B)). In the photocatalytic degradation of 2-propanol in water, the sample with a suitable amount of graphene content exhibited a higher photocatalytic performance compared to that of the original $\mathrm{TiO}_{2} / \mathrm{MCM}-41$. A moderate amount of graphene modification was found to be effective for the enhancement of the photocatalytic performance of $\mathrm{TiO}_{2} / \mathrm{MCM}-41$ (Fig. 12(B)), since modification of an excess amount of graphene interrupts incident light and limits the diffusion of reactant molecules, which rather have adverse effects on the photocatalytic performance.

4.5. $\mathrm{TiO}_{2}-\mathrm{Macroporous/mesoporous} \mathrm{silica} \mathrm{composite}$ photocatalysts

Nano-spaces in zeolite and mesoporous silica materials with pore diameters less than $50 \mathrm{~nm}$ have extensively used for the design of catalytic and photocatalytic materials. However, the role of macroporous silicate materials having larger nano-spaces (greater than $50 \mathrm{~nm}$ ) as hosts has rarely been investigated. Threedimen sionally ordered macroporous (3DOM) structures in $\mathrm{SiO}_{2}$, $\mathrm{Al}_{2} \mathrm{O}_{3}$ and other inorganic oxides can be designed using a hard template. ${ }^{107-112}$ Spherical polymers such as polystyrene (PS) and poly(methyl methacrylate) (PMMA) are utilized as hard templates, which are easily removed from the products by simple calcination in air, and thus inverse structures reflecting the periodic structure of aligned polymer particles can be obtained. We have reported a syn thesis of porous silica materials with hierarchical macroporous and mesoporous architectures (MacroMeso- $\mathrm{SiO}_{2}$ ) for utilization as supports of $\mathrm{TiO}_{2}$ photocatalysts. ${ }^{113}$ MacroMeso-SiO 2 was successfully prepared by the combined use of a typical precursor solution for the synthesis of mesoporous silica containing cationic surfactants $\left(\mathrm{Meso}-\mathrm{SiO}_{2}\right)$ and close-packed PMMA particles (Fig. 13(A)). Macroporous silica $\left(\mathrm{Macro}_{-} \mathrm{SiO}_{2}\right)$ was also synthesized via the same procedures without use of the former surfactant solution. Hierarchical macroporous and ordered mesoporous architectures were retained even after loading $\mathrm{TiO}_{2}$ on to these porous silicas by the conventional impregnation method. A FE-SEM image of $\mathrm{TiO}_{2} / \mathrm{MacroMeso-SiO}$ clearly showed the presence of interconnecting macroporous networks (Fig. 13(B)). The neighboring macropores were connected by three round holes shown as black dots on the in side wall of each macropore in the FE-SEM image. The walls separating two neighboring macropores (thickness: B $50 \mathrm{~nm}$ ) consist of ordered mesoporous structures. The macropores of $\mathrm{TiO}_{2} / \mathrm{MacroMeso}-\mathrm{SiO}_{2}$ uniformly segmentalized the structure of $\mathrm{TiO}_{2} / \mathrm{Meso}-\mathrm{SiO}_{2}$, which leads to the formation of an increased number of mesopore entrances and shortening of the mesoporous channel length. Fig. 13(C and D) shows the adsorption profiles and photocatalytic decolorization rates of methylene blue (MB) on $\mathrm{TiO}_{2} /$ MacroMeso$\mathrm{SiO}_{2}, \mathrm{TiO}_{2} / \mathrm{Meso}-\mathrm{SiO}_{2}, \mathrm{TiO}_{2} / \mathrm{Macro}_{-} \mathrm{SiO}_{2}$ and bulk $\mathrm{TiO}_{2}(\mathrm{P} 25)$ as a reference. $\mathrm{TiO}_{2} / \mathrm{MacroMeso}-\mathrm{SiO}_{2}$ showed a relatively large adsorption

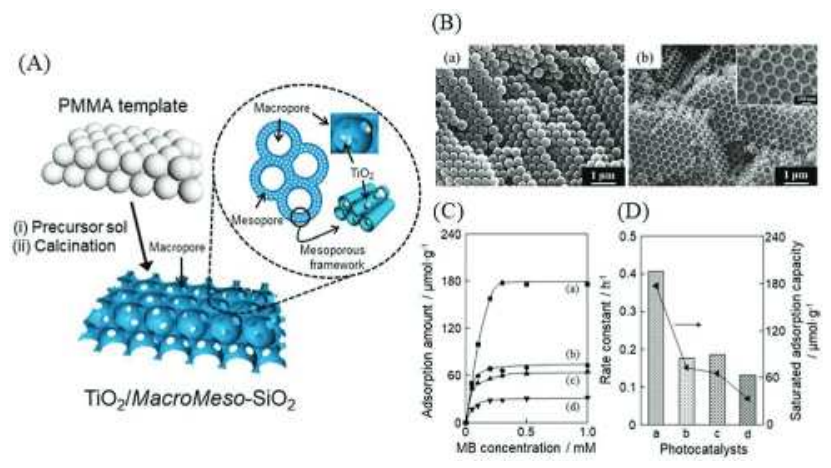

Fig. 13 (A) Schematic diagram of the procedures for the synthesis of $\mathrm{TiO}_{2} /$ MacroMeso-SiO 2 , (B) FE-SEM images of (a) PMMA particles and (b) $\mathrm{TiO}_{2} /$ MacroMeso- $\mathrm{SiO}_{2}$, (C) adsorption isotherms of $\mathrm{MB}$ and (D) relationship between the rate constants of the photocatalytic decolourization of $\mathrm{MB}$ and saturated adsorption capacities for $\mathrm{MB}$ diluted in water with different photocatalysts ((a) $\mathrm{TiO}_{2} /$ MacroMeso- $\mathrm{SiO}_{2}$; (b) $\mathrm{TiO}_{2} / \mathrm{Meso}-\mathrm{SiO}_{2}$; (c) $\mathrm{TiO}_{2} /$ Macro- $\mathrm{SiO}_{2}$; and (d) $\mathrm{TiO}_{2}$ (P25)). Reproduced from ref. 113 with permission from The Royal Society of Chemistry.

capacity of $\mathrm{MB}$, whereas the surface area and pore volume were less than half of those of $\mathrm{TiO}_{2} / \mathrm{Meso}-\mathrm{SiO}_{2}$ and $\mathrm{TiO}_{2} / \mathrm{Macro}-\mathrm{SiO}_{2}$. In the series of samples examined, $\mathrm{TiO}_{2} / \mathrm{MacroMeso-} \mathrm{SiO}_{2}$ showed a superior adsorption capability and a higher photocatalytic decolorization activity for $\mathrm{MB}$ in water, in which a strong correlation was observed between the adsorption capacities and apparent rate constants. Thus, the combination of hierarchical macroporous and mesoporous architectures in a support can offer the $\mathrm{TiO}_{2}$ photocatalyst a superior adsorption capability to condense organic compounds and photocatalytic performance effective for water purification.

\subsection{Core-shell/yolk-shell $\mathrm{TiO}_{2}-\mathrm{SiO}_{2}$ composite photocatalysts}

4.6.1. Core-shell $\mathrm{TiO}_{2} /$ silica photocatalysts. Thanks to the progress of colloid chemistry, a number of synthetic approaches to fabricate porous silicate materials with tunable nanoarchitecture, controlled composition, and multifunctionalities by changing the preparation procedures have recently been reported. ${ }^{114} \mathrm{An}$ example to improve the photocatalytic performance of $\mathrm{TiO}_{2}$ is the direct coating of $\mathrm{TiO}_{2}$ particles with a flexible mesoporous $\mathrm{SiO}_{2}$ layer, which results in the formation of a core-shell $\mathrm{TiO}_{2} @ \mathrm{SiO}_{2}$ structure. ${ }^{15,116}$ Integration of individual functions in the $\mathrm{TiO}_{2}$ core and the mesoporous $\mathrm{SiO}_{2}$ shell is expected to offer advanced and synergistic functions. We prepared a coreshell type $\mathrm{TiO}_{2} /$ mesoporous $\mathrm{SiO}_{2}$ photocatalyst $\left(\mathrm{TiO}_{2} @ \mathrm{MS}\right.$ ) through a mesoporous $\mathrm{SiO}_{2}$ (MS) coating process of spherical $\mathrm{TiO}_{2}$ particles. ${ }^{117}$ FE-SEM and TEM images clearly show that the spherical $\mathrm{TiO}_{2}$ (core) was uniformly covered by the MS layer (shell). The homogeneity in particle size was also observed in the dynamic light scattering (DLS) measurement. Since the zetapotential of $\mathrm{SiO}_{2}$ is more negative compared to that of $\mathrm{TiO}_{2}$ in a wide $\mathrm{pH}$ region, the point of zero charge (pzc) decreases from B 5.6 in spherical $\mathrm{TiO}_{2}$ to B 3.4 in $\mathrm{TiO}_{2} @ \mathrm{MS}$. Therefore, $\mathrm{TiO}_{2} @ \mathrm{MS}$ exhibits good affinity toward cationic dye (e.g. methylene blue (MB)) in water compared to the original $\mathrm{TiO}_{2}$. 
In the photocatalytic degradation of $\mathrm{MB}$ in water, $\mathrm{TiO}_{2} @ \mathrm{MS}$ exhibited a much higher decolorization rate than uncoated spherical $\mathrm{TiO}_{2}$ and bulk $\mathrm{TiO}_{2}$ (ST-01), demonstrating that the MS layer in the outer shell region of $\mathrm{TiO}_{2} @ \mathrm{MS}$ serves as a good adsorbent to accumulate $\mathrm{MB}$ near the active $\mathrm{TiO}_{2}$ surface.

4.6.2. Yolk-shell $\mathrm{TiO}_{2} @$ hollow silica photocatalysts. Hollowstructured silica can be a viable support for a $\mathrm{TiO}_{2}$ photocatalyst. The so-called yolk-shell nanostructured catalyst composed of a catalytically-active core material and an outer porous silica shell is an emerging class of material. The outer shell layer works as molecular sieves to improve the adsorption properties and as a physical barrier to protect the core material from external environments. Furthermore, the core materials encapsulated within the shell can keep their surface "free", thereby allowing them to retain their inherent catalytic activities. ${ }^{18-121}$ For example, Ikeda et al. synthesized a rattle-like $\mathrm{TiO}_{2} @ \mathrm{SiO}_{2}$ composite, con taining $\mathrm{TiO}_{2}$ nanoparticles in side the hollow silica, by a layerby-layer fabrication technique. ${ }^{122-124}$ They demonstrated that the composite showed a photocatalytic performance comparable to or even better than naked $\mathrm{TiO}_{2}$, due to the existence of the void space between the core $\left(\mathrm{TiO}_{2}\right)$ and the shell $\left(\mathrm{SiO}_{2}\right)$, which keeps the surface of $\mathrm{TiO}_{2}$ free and allows diffusion of small reactant molecules to the $\mathrm{TiO}_{2}$. Yang et al. developed a method to synthesize $\mathrm{TiO}_{2}$ particles encapsulated in hollow silicas using poly(methacrylic acid) (PMAA) as an organic template. ${ }^{125}$ Wu et al. fabricated a similar yolk-shell $\mathrm{TiO}_{2} @ \mathrm{SiO}_{2}$ composite by utilizing two kinds of polyelectrolytes with different electric charges as templates. ${ }^{126}$ However, most of the techniques require complex multiple preparation steps to achieve ideal $\mathrm{TiO}_{2} @ \mathrm{SiO}_{2}$ configurations and severe control of synthetic condition s to create porous silica shells.

Recently, we reported an alternative facile method to prepare $\mathrm{TiO}_{2}$ nanoparticles encapsulated in hollow silica spheres $\left(\mathrm{TiO}_{2} @ \mathrm{HSS}\right)$ using an oil-in-water $(\mathrm{O} / \mathrm{W})$ microemulsion as an organic template. ${ }^{127,128}$ FE-SEM and TEM images revealed that $\mathrm{TiO}_{2}$ nanoparticles (Evonik, $\mathrm{P} 25^{\mathrm{s}}$ ) are successfully encapsulated within the hollow silica spheres with a particle size of B $160 \mathrm{~nm}$ and a shell thickness of B $20 \mathrm{~nm}$ (Fig. 14(A)). The resulting yolkshell nanostructured $\mathrm{TiO}_{2} @ \mathrm{SiO}_{2}$ composite exhibited both improved adsorption properties and catalytic efficiency in the photocatalytic decomposition of VOCs (acetaldehyde and 2-propanol), which markedly exceeded those of unprotected $\mathrm{TiO}_{2}$. Reaction profiles and comparative studies revealed that this is attributed to the ability of the porous silica shell to adsorb/enrich small VOC molecules inside of the void space and efficient transportation to the adjacent active $\mathrm{TiO}_{2}$ core material (Fig. 14(B)).

Furthermore, the protective porous silica shell endowed this material with molecular-sieving properties, indicating the possibility for the combined use with organic support materials such as organic binders, polymer films, and organic fibers. We combined $\mathrm{TiO}_{2} @ \mathrm{HSS}$ particles with a cellulose fiber (CF) to fabricate composite papers with photocatalytic functionality and high durability even under UV-light irradiation (Fig. 15). ${ }^{129}$ The fabrication of the composite papers was performed via physical adhesion process using a dual polymer system. The fabricated $\mathrm{TiO}_{2} @ \mathrm{HSS} /$ paper provided a high photocatalytic activity in the
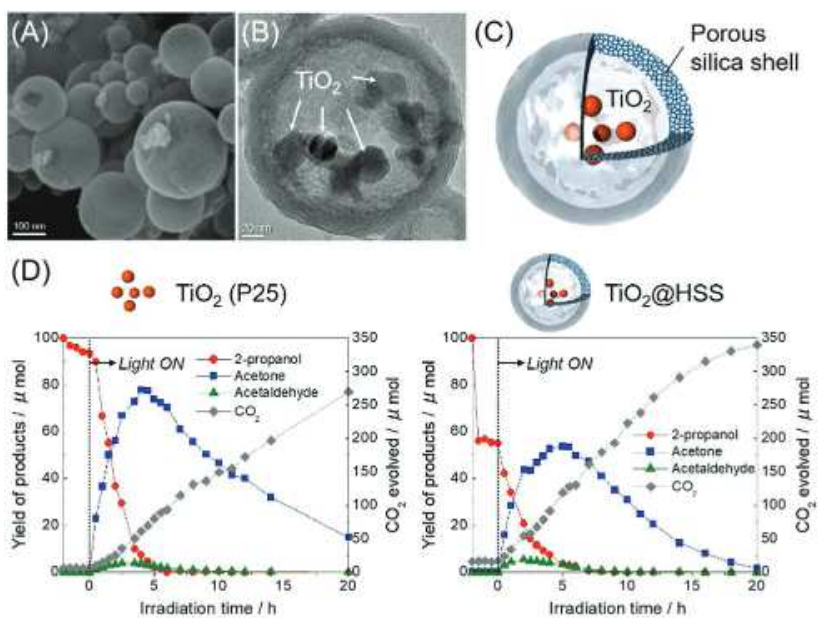

Fig. 14 (A) FE-SEM and (B) TEM images and (C) illustration of a $\mathrm{TiO}_{2} @ \mathrm{HSS}$ composite photocatalyst. (D) Reaction kinetics in the photocatalytic degradation of 2-propanol in air over (left) commercial $\mathrm{TiO}_{2}$ (Evonik, P25 ${ }^{\mathrm{s}}$ ) and (right) the $\mathrm{TiO}_{2} @ \mathrm{HSS}$ composite photocatalyst under UV light irradiation. Reproduced from ref. 127 with permission from John Wiley and Sons.

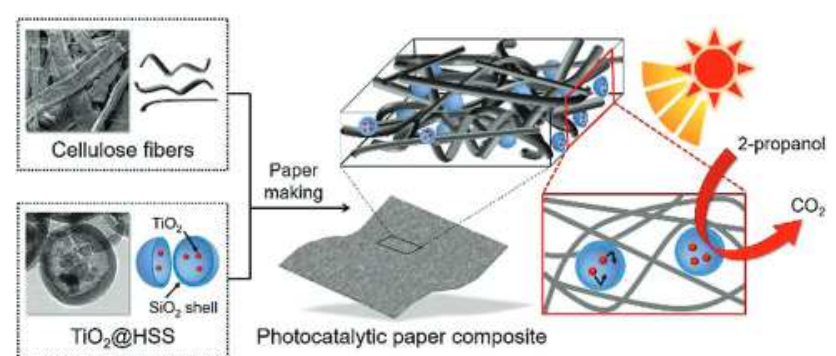

Fig. 15 Schematic illustration for the fabrication protocol of a photocatalytic paper composite consisting of cellulose fibers and $\mathrm{TiO}_{2} @ \mathrm{HSS}$ photocatalyst particles. Reproduced from ref. 129 with permission from American Chemical Society.

degradation of VOCs diluted in air similar to or even higher than sole $\mathrm{TiO}_{2} @ \mathrm{HSS}$ particles because of the reticular fiber network and high air permeability of the paper. The paper support was hardly degraded by $\mathrm{TiO}_{2}$ photocatalysis, while retaining its ten sile strength even after long-term UV light irradiation, which was due to the ability of the silica shell as a physical barrier to prevent direct contact between $\mathrm{CFs}$ and $\mathrm{TiO}_{2}$ particles. Thus the fabricated photocatalytically active paper is easy to handle and shows higher photocatalytic performances in the degradation of VOCs compared with the bare $\mathrm{TiO}_{2}$ particles, making it as a promising candidate for real application in air cleaning.

\section{Thin film photocatalysts}

Coating technologies are able to control the surface wettability of materials. Two states in a solid surface, i.e., hydrophilic state and hydrophobic state, are often categorized according to the behavior of the water droplet. The hydrophilic state shows a water contact angle (y) less than 901 Materials with hydrophilic surfaces easily get wet by water. In particular, a water droplet rapidly and uniformly spreads on a superhydrophilic surface 
(y: less than 51). Antifogging mirrors, glasses and outward walls of buildings are commercialized using hydrophilic coating technologies. ${ }^{80,130}$ Meanwhile, the hydrophobic state shows a water contact angle greater than 901 Materials with hydrophobic surfaces repel water droplets. In particular, the water droplet has a spherical shape on the superhydrophobic surface (y: larger than 1501). Waterproof, antifogging, the effect of a decrease in surface friction and accretion of ice and snow are realized as specific functions by utilization of the hydrophobic coating technologies. ${ }^{131-134}$ The following section summarizes our recent studies about the coating technologies for the design of superhydrophilic and superhydrophobic thin films.

\section{1. $\mathrm{TiO}_{2}$ thin films for superhydrophilic coatings}

$\mathrm{TiO}_{2}$ is well-known as an efficient photocatalyst for environmental remediation and energy related issues. ${ }^{80,135,136}$ After the discovery of the photoinduced superhydrophilicity of a $\mathrm{TiO}_{2}$ surface in 1997, many researchers have focused on $\mathrm{TiO}_{2}$ as a multifunctional material for superhydrophilic coatings with photocatalytic self-cleaning properties. ${ }^{80,137,138}$ The oily dirt is easily removable due to the photocatalytic properties of $\mathrm{TiO}_{2}$. The sol-gel method, chemical vapor deposition (CVD) and sputtering deposition are mainly used for $\mathrm{TiO}_{2}$ coatings. ${ }^{139-143}$ The architectures of the $\mathrm{TiO}_{2}$ surface are important in relation to noticeable phenomena such as photoinduced hydrophilicity and photocatalytic self-cleaning properties. In this regard, we carried out the design of $\mathrm{TiO}_{2}$ thin films with a macroporous structure on a quartz substrate $\left(\mathrm{m}-\mathrm{TiO}_{2} / \mathrm{Q}\right)$ by a combination of the sol-gel technique and the template strategy (Fig. 16). ${ }^{143,144}$

Pre-coated poly(methyl meth acrylate) (PMMA) microspheres on a quartz substrate were used as a hard template for the construction of a macroporous structure, which was easily removable by heat treatment or solvent extraction. For comparative studies, $\mathrm{TiO}_{2}$ thin films were also directly prepared on a quartz substrate $\left(\mathrm{TiO}_{2} / \mathrm{Q}\right)$ using the same precursor sol. The positive effect of the macroporous structure on the surface wettability changes and photocatalytic performance in the degradation of volatile organic compounds (VOCs) was clearly observed

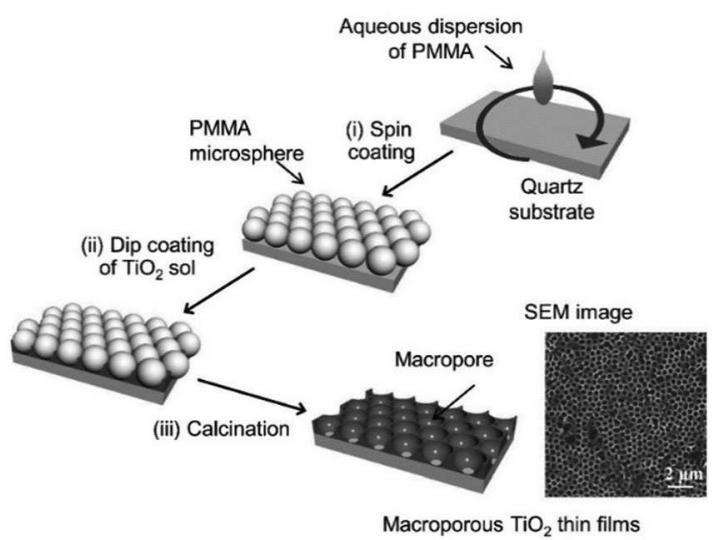

Fig. 16 A schematic diagram of the procedures for the preparation of macroporous $\mathrm{TiO}_{2}$ thin films. Reproduced from ref. 143 with permission from The Royal Society of Chemistry. in $\mathrm{m}-\mathrm{TiO}_{2} / \mathrm{Q}$. After a short period of UV light irradiation, the water contact angle on $\mathrm{m}-\mathrm{TiO}_{2} / \mathrm{Q}$ became lower than 51 The rougher surfaces of the $\mathrm{TiO}_{2}$ thin films exhibit a faster change from the hydrophobic to hydrophilic state under UV light irradiation. ${ }^{145}$ The macroporous structure in $\mathrm{m}-\mathrm{TiO}_{2} / \mathrm{Q}$ induced a quick change in surface wettability. When kept in the dark after UV light irradiation, $\mathrm{m}-\mathrm{TiO}_{2} / \mathrm{Q}$ shows a slow recovery of water contact angles compared to that on $\mathrm{TiO}_{2} / \mathrm{Q}$. The surface wettability gradually changed from the superhydrophilic state to its original state in the dark. Agood durability of the hydrophilic surface in the dark was also achieved by the construction of a macroporous structure. Moreover, in the degradation of acetaldehyde in air, $\mathrm{m}-\mathrm{TiO}_{2} / \mathrm{Q}$ showed higher photocatalytic performance than $\mathrm{TiO}_{2} / \mathrm{Q}$. ${ }^{143}$ The macroporous structure in $\mathrm{m}-\mathrm{TiO}_{2} / \mathrm{Q}$ was also quite effective for the improvement of the self-cleaning properties and maintaining a clean environment.

\subsection{Porous silica thin films for superhydrophilic coatings}

Isolated tetrahedrally coordinated transition metal species can be designed within the matrixes of porous siliceous materials. ${ }^{146,147}$ Porous silica thin films have been prepared by wet chemical processes such as spin-coating and dip-coating methods. ${ }^{23,148,149}$ Controlling the chemical composition of the precursor solution, isolated tetrahedrally coordinated transition metal species are successfully incorporated within the porous silica framework. We carried out the design of tetrahedral Ti-containing mesoporous silica thin films (TiMSF) on a quartz glass substrate via a spin-coating method. ${ }^{21,150-154}$ The TiMSF shows unique surface wettability in water contact angle measurements. The water contact angles on the pure mesoporous silica thin films (MSF) were 20-301 (Fig. 17). Incorporation of Ti-species within silica matrixes realized surface wettability changes. The water contact

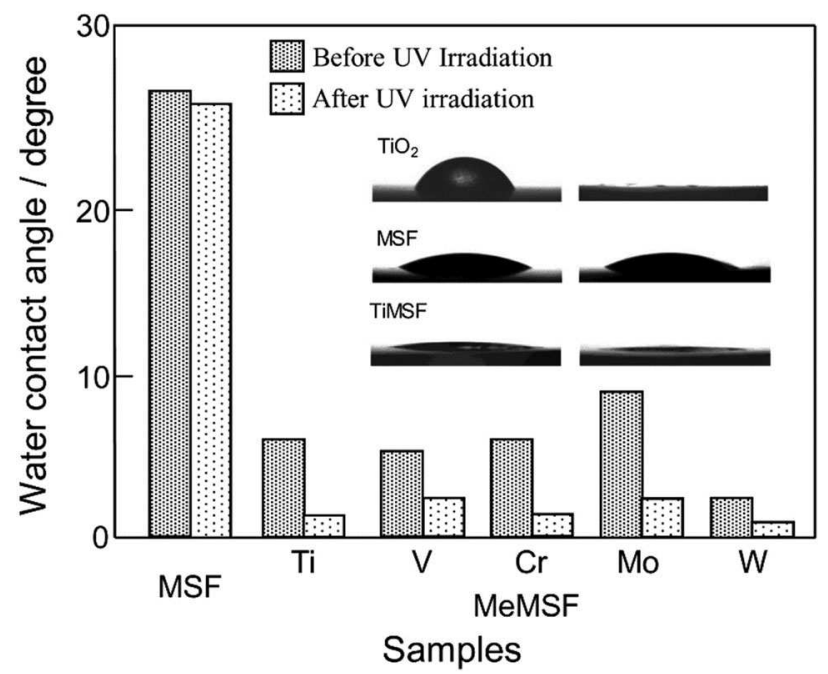

Fig. 17 Contact angles of water droplets on a MSF and tetrahedral transition metal (Me)-containing MSF (MeMSF, Me = Ti, V, Cr, Mo, and W) before and after UV light irradiation. The inset shows photographic images of the water droplet on each sample before and after UV light irradiation (irradiation time: $3 \mathrm{~h}$ ). Reproduced from ref. 158 with permission from The Elsevier B.V. 
angle on the TiMSF was smaller than 101. Compared to the surface wettability of $\mathrm{TiO}_{2}$ th in films, the TiMSF has a relatively hydrophilic surface even before UV light irradiation. The TiMSF showed changes in surface wettability to a highly hydrophilic state after UV light irradiation. This behavior is similar to the property of bulk $\mathrm{TiO}_{2}$ thin films. The surface wettability of the MSF scarcely ch an ged under UV light irradiation. The tetrahedral Ti species in a mesoporous silica matrix play a significant role in the improvement of hydrophilic properties. The differences in the architectures directly influence the surface properties of the TiMSF. The combination of macroporous and mesoporous structures as well as the roles of tetrahedral Ti-species led to a significant improvement of surface hydrophilicity compared to that on the TiMSF. ${ }^{155}$ Moreover, the incorporation of the other kinds of transition metal oxide species (e.g. V, Cr, Mo, W, etc.) instead of tetrahedral Ti-species was effective for the improvement of the surface hydrophilicity of the MSF. ${ }^{21,151,156,157}$ Among of them, a tetrahedral Cr-containing mesoporous silica thin films (CrMSF) showed superhydrophilicity even after visible light irradiation, which had possibilities for application in indoor uses. ${ }^{27,29,34}$ The water contact angle on the tetrahedral W-containing mesoporous silica thin film (WMSF) was B 31, and changed to almost 01 after UV light irradiation. The WMSF showed the highest hydrophilic properties among the evaluated samples and exhibited a long durability of the superhydrophilic state in the dark. ${ }^{157}$

\subsection{Nanocomposite materials for superhydrophobic coatings}

5.3.1. Superhydrophobic surfaces designed by the catalysis of coated materials. Nanocomposite coatings are effective tools for superhydrophobic coatings on various materials. Controlling the chemical compositions for lowering the surface energies and geometric structures of solid surfaces in a micro- or nanoscale is indispensable for the design of artificial hydrophobic surfaces. ${ }^{156,159-162}$ Composite coatings of carbon materials, fluorine-containing polymers and other desired materials are widely investigated by many researchers for the design of superhydrophobic surfaces. ${ }^{163-166}$ In this regard, we carried out the design of superhydrophobic surfaces by uses of catalytic properties in coated materials. The surface modification by polyethylene (PE) synthesis was realized by the photocatalytic polymerization of ethylene. ${ }^{167}$ In this case, tetrahedral $\mathrm{Cr}$-containing colloidal silica n an oparticles ( $\mathrm{Cr} / \mathrm{SNPs})$ were used as a coating material of the quartz substrate. Cr/SNPs had two roles in the formation of surface roughness and photocatalyst for surface modification (Fig. 18). Photocatalytic activity for the polymerization of ethylene on tetrahedral $\mathrm{Cr}$-species was reported under UV and visible light irradiation. ${ }^{151,157,168}$ Before UV light irradiation, the Cr/SNP-coated quartz substrate showed hydrophilicity. After surface PE modification through the photocatalytic ethylene polymerization, the water contact angle reached B 1621. These thin films have a high transparency and sufficient superhydrophobic properties.

Moreover, the surface modification with carbon nanotubes (CNTs) was also performed on tetrahedral Ti-containing mesoporous silica thin films (TiMSF) with a Co-Mo catalyst. ${ }^{169}$

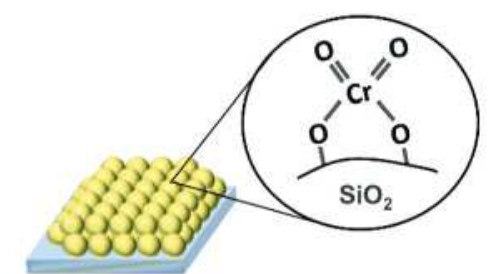

Self-assembly of Cr/SNPs

Photocatalytic polymerization of ethylene (a)

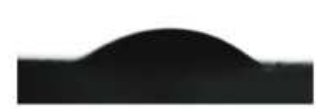

(b)

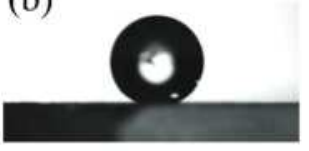

Fig. 18 Schematic image of Cr/SNP-coated glass and photographic images of the water droplet before (a) and after (b) the photocatalytic polymerization of ethylene. Reproduced from ref. 167 with permission from The Royal Society of Chemistry.

The highly dispersed Co-Mo catalyst was successfully deposited on the TiMSF under microwave irradiation $(500 \mathrm{~W} ; 2450 \mathrm{MHz})$. The Co-Mo catalyst was not uniformly formed on the MSF without the incorporation of Ti-species and by conventional thermal heating, indicating that Ti-species play important roles in anchoring the Co-Mo catalyst. ${ }^{170}$ The Co-Mo catalyst on the TiMSF was used for CNT synthesis by the decomposition of alcohol vapor at elevated temperature. The water contact angle reached 1651 after surface modification with CNTs, which showed a good superhydrophobic property.

5.3.2. Superhydrophobic surfaces with photocatalytic self-cleaning properties. In recent years, the design of superhydrophobic surfaces with additional functions is investigated by many researchers. External stimuli, i.e., light, temperature, $\mathrm{pH}$ and others, induce reversible switching of surface wettability. ${ }^{171-177} \mathrm{TiO}_{2}$ is an external stimulus sensitive material and promising for superhydrophilic coatings with self-cleaning properties. However, the combination of hydrophobic materials and $\mathrm{TiO}_{2}$ has not yet received a full investigation. Due to their inherent properties, combination of hydrophobic materials and $\mathrm{TiO}_{2}$ is not so easy. In this regard, we found that the nanocomposite coating of $\mathrm{TiO}_{2}$ and polytetrafluoroethylene (PTFE) prepared by a radiofrequency-magnetron sputtering (RF-MS) deposition provides a superior hydrophobicity with a photocatalytic self-cleaning effect. ${ }^{178-180} \mathrm{The}^{\mathrm{TiO}_{2}}$ and PTFE composite film was prepared on a quartz and structured Ti substrate $\left(\mathrm{TiO}_{2}-\mathrm{PTFE} / \mathrm{Ti}\right)$. Each component was uniformly accumulated on the structured Ti substrate without large geometric changes. The water contact angle was below 1201 on the flat samples such as $\mathrm{TiO}_{2}-\mathrm{PTFE}$ composites and PTFE film surfaces. $\mathrm{TiO}_{2}-\mathrm{PTFE} / \mathrm{Ti}$ fulfilled the definition of a superhydrophobic surface (Fig. 19). The water contact angle reached $\mathrm{B} 1571$ on $\mathrm{TiO}_{2}-\mathrm{PTFE} / \mathrm{Ti}$. Under UV light irradiation, the $\mathrm{TiO}_{2}$ surface was gradually hydrophilized and finally achieved a superhydrophilic state. However, $\mathrm{TiO}_{2-}$ PTFE/Ti maintained the superhydrophobic state even after UV light irradiation. The chemical composition plays important roles in this system. The two domains mixed in the nanoscale possess the hydrophilic and hydrophobic natures, which maintained the 


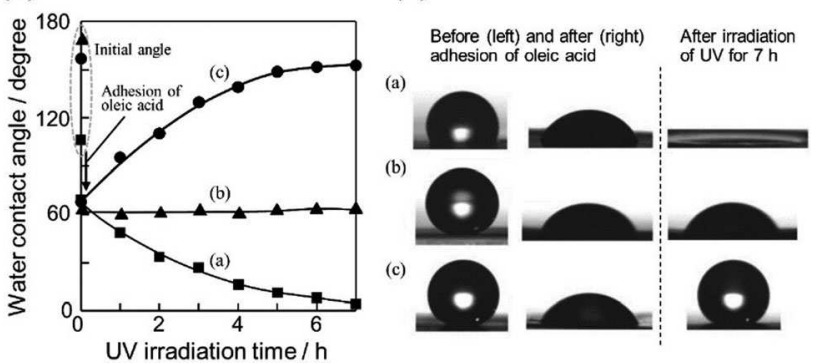

Fig. 19 (A) Water contact angle changes and (B) photographic images of the water droplet on each sample by adhesion of oleic acid and following UV light irradiation ((a) $\mathrm{TiO}_{2} / \mathrm{Ti}$, (b) PTFE/Ti, and (c) $\left.\mathrm{TiO}_{2}-\mathrm{PTFE} / \mathrm{Ti}\right)$. Reproduced from ref. 178 with permission from John Wiley and Sons.

good water-repellent properties of $\mathrm{TiO}_{2}-\mathrm{PTFE} / \mathrm{Ti}$. The surface wettability change was observed in the $\mathrm{TiO}_{2}$ rich composite of $\mathrm{TiO}_{2}-\mathrm{PTFE}$ under the same conditions. In practical uses, the performance of hydrophobic coatings gradually decreases by adhesion of oily dirt. The water repellent properties easily disappeared and did not recover without the mainten ance process by washing. Oily dirt can be easily removed by the photocatalytic self-cleaning effect of $\mathrm{TiO}_{2}$. The self-cleaning properties of $\mathrm{TiO}_{2}-\mathrm{PTFE} / \mathrm{Ti}$ were confirmed by the decomposition of oleic acid as a model contaminant (Fig. 19). After adhesion of oleic acid, the water contact angle immediately changed to around 651 By the photocatalytic decomposition of oleic acid and the effect of photoinduced surface hydrophilicity, the water contact angle on $\mathrm{TiO}_{2}$ changed to almost 01 after UV light irradiation. The superhydrophobicity of PTFE/Ti hardly recovered without washing with an organic solvent. $\mathrm{TiO}_{2}-\mathrm{PTFE} / \mathrm{Ti}$ showed unique response and gradual increases in the water contact angle to its original superhydrophobic state. The photocatalytic selfcleaning properties of the $\mathrm{TiO}_{2}$ domain showed sufficient performance for the removal of oleic acid. Nanocomposites of $\mathrm{TiO}_{2}$ and PTFE realized a use of photocatalytic self-cleaning properties on superhydrophobic surfaces. The simultaneous use of self-cleaning properties as an additional function is useful for maintaining a clean surface.

\section{Ag-Based plasmonic catalysts confined within mesoporous silica}

The efficient light absorption by noble metal NPs in the visible region of the solar spectrum recently became very popular due to their high absorption intensity. ${ }^{181}$ The absorption intensity can be easily tuned by modifying their size, morphology and composition. This branch of photocatalysis, popularly known as plasmonic photocatalysis, has seen tremendous growth in the sustainable development of energy and the environment. ${ }^{182,183}$ Over the past two decades, plasmonics grew out of the exten sive research in the frame of nanotechnology in diverse areas of electronics, photocatalysis, photovoltaics, biosensing and artificial photosynthesis. ${ }^{20,184-186}$ Noble metal NPs (e.g., silver and gold), immobilized on a suitable support material, can be excited

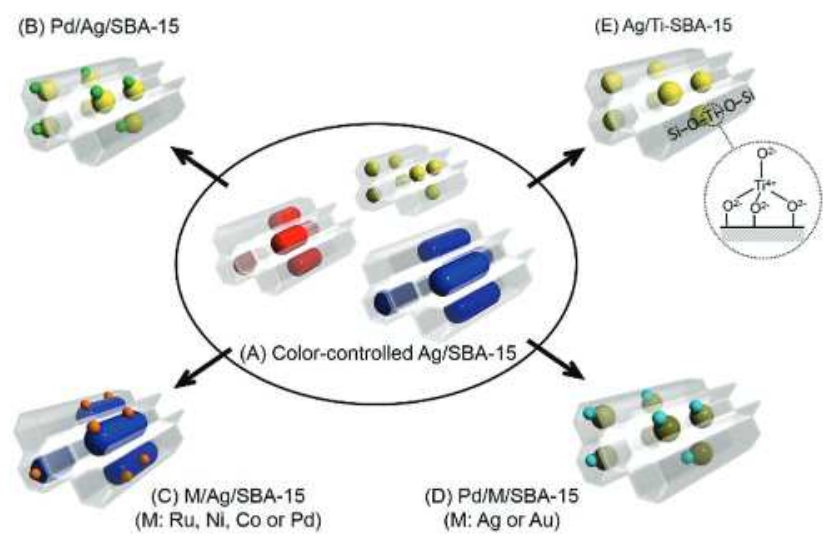

Fig. 20 Schematic outline of the plasmonic catalysts prepared with confined mesopores.

by light absorption to drive chemical reactions on its surface. Over the past few years, Ag has attracted significant attention to be used as a plasmonic photocatalyst due to its low cost and distinctively strong absorption in the visible spectrum of solar light irradiation. ${ }^{187}$ Numerous reports have been published focusing on the direct plasmonic catalysis by Ag NPs, supported on insulator support materials, due to their enhanced photocatalytic quantum efficiency. ${ }^{188}$ Among the insulating solid supports, hexagonal mesoporous silica SBA-15 acts as a promising platform for NPs to couple the incident light energy on the surfaces of plasmonic metal NPs because of its optical transparency in the visible light region. In this section, the syn thetic strategy, characterization and properties of Ag-based plasmonic nanocatalysts utilized for efficient catalytic reactions under visible light irradiation conditions are summarized (Fig. 20).

\subsection{Color-controlled Ag-based plasmonic catalysts}

We have synthesized the size- and morphology-controlled Ag plasmonic NPs supported on mesoporous silica SBA-15 by a new method in which the color of the Ag NPs can be altered by changing the irradiation times of microwave (MW) heating. ${ }^{19,189}$ The support material SBA-15 mesoporous silica has a regular one-dimensional and hexagonally ordered structure. Three types of Ag NPs were prepared within the confined mesopores of SBA- 15 by a MW-assisted alcohol reduction method upon varying the irradiation time from 3 to $5 \mathrm{~min}$ in the presence or absence of a surface modifying agent, i.e. sodium laurate (Lau) $\mathrm{CH}_{3}\left(\mathrm{CH}_{2}\right)_{10} \mathrm{COONa}$. A spherical yellow colored Ag catalyst, denoted Ag/SBA-15 (Y), was synthesized by preparing a suspension of silica in 1-hexanol, an aqueous $\mathrm{AgNO}_{3}$ solution and Lau followed by MW heating of 3 min under an Ar atmosphere. Red Ag/SBA-15 (R) and blue Ag/SBA-15 (B) catalysts were synthesized using a similar procedure in the absence of a surfactant with MW heating times of 3 and $5 \mathrm{~min}$, respectively (Fig. 20A).

As can be seen from the TEM micrographs (Fig. 21(a-c)), nanosized Ag NPs were successfully deposited within the wellordered mesoporous channel structure of SBA-15. The mean diameter of the yellow NPs, and the aspect ratios of the red and 


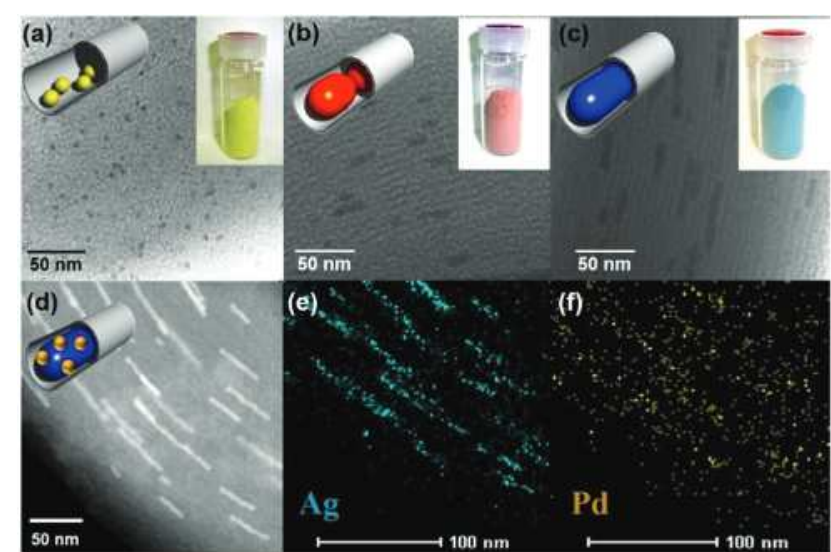

Fig. 21 TEM micrographs of size and color controlled $\mathrm{Ag}$ and $\mathrm{Pd} / \mathrm{Ag} N \mathrm{~N}$ : (a) Ag/SBA- 15 (Y), (b) Ag/SBA- 15 (R), (c) Ag/SBA- 15 (B), and (d) Pd/Ag/SBA15 (B), and (e and f) elemental mapping of $\mathrm{Ag}$ and $\mathrm{Pd}$ in $\mathrm{Pd} / \mathrm{Ag} / \mathrm{SBA}-15$ (B).

blue nanorods were found to be $4 \mathrm{~nm}, 2.8 \mathrm{~nm}$ and $6.1 \mathrm{~nm}$, respectively. The optical absorption of the three different NPs showed the characteristic plasmonic absorption peak at $400 \mathrm{~nm}$, and an additional peak centered at $l=1200 \mathrm{~nm}$ was observed for $\mathrm{Ag} / \mathrm{SBA}-15$ (B). The two absorption peaks for Ag/SBA-15 (R) and $\mathrm{Ag} / \mathrm{SBA}-15$ (B) in the visible and infrared regions were assigned to the transverse (perpendicular) and lon gitudinal (parallel) modes of the $\mathrm{Ag}$ nanorods, respectively.

The effects of the size and color of Ag NPs were in vestigated in their catalytic performance ability in the $\mathrm{H}_{2}$ production from ammonia borane $\left(\mathrm{NH}_{3} \mathrm{BH}_{3}+2 \mathrm{H}_{2} \mathrm{O}-\mathrm{NH}_{4}{ }^{+}+\mathrm{BO}_{2}{ }^{{ }^{5}}+3 \mathrm{H}_{2}\right) \cdot{ }^{190,191}$ The smallest yellow NPs were the most efficient followed by red and then blue. Upon visible light irradiation (1 $4420 \mathrm{~nm}$, $320 \mathrm{~mW} \mathrm{~cm}{ }^{52}$ ), all Ag NPs showed enhanced catalytic performances owing to the LSPR effect, which increased in the following order: yellow $(29 \%) \circ$ red $(66 \%) \circ$ blue $(124 \%)$. The light originating from the Xe lamp contain s not only visible light but also a part of infrared light. So, it can be suspected that the enhancement of catalytic activity can be due to the thermal effect arising from infrared light. It was observed that the overall temperature of the reaction solution increased by $51 \mathrm{C}$ under light irradiation conditions in the case of Ag/SBA-15 (B), due to its wide LSPR absorption arising from the longitudinal mode of the nan orods. We carried out the thermal reaction at $30 \mathrm{IC}$ under dark conditions, in order to elucidate the effect of thermal heating. The observed catalytic activity was found to be slightly higher than the measured activity under dark conditions but significantly lower than that measured under light irradiation conditions, which confirmed the negligible contribution of temperature to the enhanced catalytic activity. Moreover, the recovered plasmonic $\mathrm{Ag}$ catalysts retained their original unique structures and colors even after the reaction, as confirmed by TEM and UV-vis spectra.

\subsection{Bimetallic $\mathrm{M} / \mathrm{Ag}-\mathrm{b} a \mathrm{sed}$ plasmonic photocatalysts}

Noble metal incorporating bimetallic n anostructures are capturing more attention in diverse areas, due to their better catalytic, optical, electrical and magnetic properties than monometallic nan ostructures. Adetailed study can indicate the significance of the relative concentration and the shapes of the metallic components. In order to improve the optical properties, catalytic activity and selectivity, the decoration of Pd NPs on the surfaces of size- and color-controlled plasmonic Ag NPs was carried out by a simple LSPR-assisted deposition method under visible light irradiation conditions (Fig. 20B and C). ${ }^{192}$ The catalysts are named $\mathrm{Pd} / \mathrm{Ag} / \mathrm{SBA}-15$ (Y), Pd/Ag/SBA-15 (R) and $\mathrm{Pd} / \mathrm{Ag} / \mathrm{SBA}-15$ (B). Fig. 21(d-f) displays the HR-TEM images and elemental mapping of uniformly deposited Pd NPs on the surfaces of the Ag nanorods for $\mathrm{Pd} / \mathrm{Ag} / \mathrm{SBA}-15$ (B).

These bimetallic NPs showed higher catalytic activities and significant enhancement effects when tested for the $A B$ dehydrogenation reaction in the dark and under light irradiation conditions. A similar trend to those of monometallic nanostructures was observed under visible light irradiation. The wavelen gth dependences of the catalytic performances over $\mathrm{Ag} / \mathrm{SBA}-15$ and $\mathrm{Pd} / \mathrm{Ag} / \mathrm{SBA}-15$ using monochromatic light $(I=400,460,650 \mathrm{~nm})$ were also explored. The increased catalytic performances were found to be in accordance with the LSPR absorption intensities of the Ag NPs, suggesting the key role of particle color in increasing the catalytic activity.

The Pd/Ag bimetallic plasmonic catalyst was also found to display an enhanced catalytic activity in the Suzuki-Miyaura coupling reaction under visible light irradiation. The above work was extended to study the effects of plasmonic $\mathrm{Au}$ and $\mathrm{Pd} / \mathrm{Au}$ nanostructures and compare their absorption and catalytic activities with $\mathrm{Ag}$ and $\mathrm{Pd} / \mathrm{Ag}$ nanocatalysts (Fig. 20D). ${ }^{193}$ The LSPR absorption peaks of the Ag, Pd/Ag and Au, Pd/Au supported catalysts exhibited characteristic absorption at approximately 400 and $520 \mathrm{~nm}$, respectively. We were able to design and syn thesize spherical nanosized $\mathrm{Pd} / \mathrm{Ag}$ and $\mathrm{Pd} / \mathrm{Au}$ nanostructures with average particle sizes of 4.2 and $4.9 \mathrm{~nm}$, respectively. $\mathrm{Pd} / \mathrm{Au}$ exhibited significant superior catalytic activity in the SuzukiMiyaura coupling reaction, while $\mathrm{Pd} / \mathrm{Ag}$ was found to be active in the $\mathrm{AB}$ dehydrogenation reaction. A plausible mechanism of the plasmonic catalysis under light irradiation conditions is proposed, in which the electron transfer from the plasmonic metal to active Pd and then to the adsorbed reactant molecules enhances bond weakening and/or cleavage. Several bimetallic combinations of catalytically active metals like Pd, Co, Ni, Ru, etc., with Ag NPs were explored in order to design visible light sensitive plasmonic nanocatalysts. ${ }^{194,195}$ The bimetallic combination with Ag NPs depends on the work function values of the active metal, which enables the lower positioning of Fermi energy level of active metal than that of $\mathrm{Ag}$. This enables the effective charge transfer pathway from $\mathrm{Ag}$ to $\mathrm{M}$ under visible light irradiation conditions. These bimetallic plasmonic systems of catalysts depicted excellent catalytic performance and visiblelight enhancements in the hydrogen production from $\mathrm{AB}$ and nitrophenol reduction using $\mathrm{AB}$ as an in situ source of $\mathrm{H}_{2}$.

6.3. Ag plasmonic photocatalysts with the assistance of single-site photocatalysts

In another strategy, a Ag-based plasmonic catalyst supported on mesoporous silica was designed with isolated and tetrahedrally 
(a)

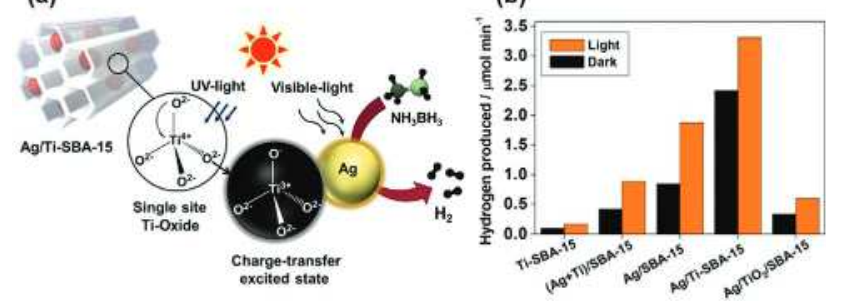

Fig. 22 (a) Schematic illustration of a light induced charge transfer pathway on the surface of the Ag/Ti-SBA- 15 catalyst under UV-vis light irradiation. (b) Reaction rates for all catalysts in the $A B$ dehydrogenation at room temperature in the dark and under light irradiation conditions.

coordinated single-site Ti-oxide moieties, namely, Ag/Ti-SBA-15, with the purpose of utilizing the broad spectral range of solar energy. ${ }^{196}$ A sharp plasmonic peak at $410 \mathrm{~nm}$ characteristic of LSPR absorption with an average particle size of $3.2 \mathrm{~nm}$ was observed for Ag/Ti-SBA-15 (Fig. 20E). In the Ag K-edge FT-EXAFS spectra, a main peak due to the contiguous $\mathrm{Ag}-\mathrm{Ag}$ bond in the metallic state was observed at $2.4 \AA$ XPS analysis also confirmed the metallic nature of Ag. Also, the peaks observed at binding energies (BE) of $375.2 \mathrm{eV}\left(3 \mathrm{~d}_{3 / 2}\right)$ and $369.3 \mathrm{eV}\left(3 \mathrm{~d}_{5 / 2}\right)$ in Ag/SBA-15 exhibited a shift towards lower values upon incorporation of Ti-oxide and $\mathrm{TiO}_{2}$ moieties. This shift confirms the possible interactions of Ti-oxide and Ag via an electron-transfer process from Ti-oxide moieties to Ag to create electron-rich Ag species, ultimately assisting in enhancing the reaction rate. Fig. 22(a) illustrates the formation of trapped hole $\left(\mathrm{Ti}^{3+}\right)$ and

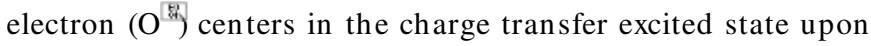
UV light irradiation in the Ti-oxide moieties. The heterojunction between $\mathrm{Ag}$ and Ti-oxide moieties allows both UV and visible light irradiation to be exploited by possible charge transfer from the excited Ti-oxide moieties to the plasmonic Ag nanostructures and further to the antibonding molecular orbitals of the adsorbed reactant species. With an optimum doping of $0.5 \mathrm{~mol} \%$ of Ti-oxide species with in the mesoporous silica framework, the reaction rate for $\mathrm{AB}$ dehydrogenation was found to be $3.3 \mathrm{mmol}^{\text {[if }}$, which was almost six times higher than that of $\mathrm{Ag} / \mathrm{TiO}_{2} / \mathrm{SBA}-15$ and two times than that of the $\mathrm{Ag} / \mathrm{SBA}-15$ catalyst without Ti species, as summarized in Fig. 22(b). The superior catalytic activities can be explained due to the unique synergistic interaction and effective charge relay of visible light sen sitive plasmonic Ag NPs with UV-active Ti-oxide species.

The efficient use of solar energy in chemical reactions by employing plasmonic photocatalysis undoubtedly represents one of the foremost techniques in order to develop and design new catalytic materials for sustain able development. It depends mainly on the material used and on its physical properties such as its size, morphology, work function, plasmonic band, hot carrier lifetime and energy distribution. To be able to tailor and fine-tune all properties is a systematic task which requires advanced synthetic methodologies and fabrication techniques. We hope that future studies will help in the better understanding of the effects arising from LSPR and on the enhancement of photocatalysis from fundamental and technical perspectives. ${ }^{197-199}$

\section{MOF-Based photocatalysts}

Metal organic frameworks (MOFs), a new class of synthetic porous materials with high crystallinity, are composed of in organic parts as connecting centers and organic parts as linkers. ${ }^{200-202}$ The inorganic part is a metal-oxygen cluster formed by the transition metal cations coordinated with the oxygen of the organic part, and the organic part is normally based on multi-dentate organic molecules with two carboxylic functional groups or electron-rich binding sites. ${ }^{202,203}$ MOFs have been demonstrated as a promising platform for the design and architecture of novel photocatalysts by taking advantage of their significant chemical diversity and structural regularity. ${ }^{204}$ Indeed, an increasing number of recent research studies have demonstrated that MOFs are emerging as a new class of photocatalysts employed in a wide range of photocatalytic applications including hydrogen $\left(\mathrm{H}_{2}\right)$ production from water, $\mathrm{CO}_{2}$ reduction, organ ic pollutant degradation, heavy metal reduction and organic transformation reactions..$^{201,205,206}$ The modular nature of MOF synthesis as well as tailorable nature allows us to rationally design and engineer the multifunctional catalytic sites in the MOF at the molecular level. In this section, the design approaches and post-modification strategies for MOF-based photocatalysts are introduced with an emphasis on engineering the catalytically active sites. According to the reported results, methodologies to design MOF photocatalysts can be simply divided into 5 branches.

\subsection{MOF semiconductors}

The integration of quantum sized-inorganic clusters and light responsive organic ligands endows MOFs with semiconducting properties. As is well known that most semiconductors are composed of transition metal cations coordinated with oxygen. In the case of MOFs, not only is the quantum sized-inorganic cluster light responsive, but also the organic linker is light responsive. Photocatalytic reactions can be easily realized by converting solar energy to chemical energy on this hybrid material under light irradiation. Taking MOF-5 ( $\mathrm{Zn}$ oxide cluster linked by 1,4-benzenedicarbolylate) as an example, ${ }^{207}$ the generation and migration of reactive charges on MOF-5 in the microsecond were observed under light irradiation, suggesting the semiconducting properties of MOF-5. The semiconducting properties of MOF-5 are further confirmed by the photocatalytic phenol degradation. $\mathrm{NH}_{2}$-MIL-125(Ti) is also used as a photocatalyst in the hydrogen production from water and conversion of $\mathrm{CO}_{2}$ to formate under visible light irradiation in the presence of sacrificial reagents. ${ }^{208,209}$

\subsection{Organometallic compounds incorporated in to MOFs}

Organometallic compounds are a class of highly effective photocatalysts, ${ }^{51,52}$ but their photocatalytic applications are significantly limited due to their low stability and unrecoverable properties. ${ }^{210,211}$ MOFs are highly crystallized solid materials offering an ideal platform for the heterogenization of homogeneous organometallic compounds. ${ }^{206,212}$ In the case of the in situ synthetic method, organometallic compounds are introduced in to the MOF synthetic precursor as ligands to link the 
metal oxide clusters. ${ }^{212,213}$ On the other hand, the postmodification strategy employs multi-dentate organic molecules with dicarboxylic groups as organic linkers, in which the dicarboxylic group coordinates with metal cations to form MOFs with free binding sites for anchoring active sites. ${ }^{214,215}$ Additionally, anchoring functional groups within the frameworks of MOFs for post-chelating active sites and post-syn thetic exchange of the organic linker with organometallic compounds has also been developed to synthesize novel MOF photocatalysts. ${ }^{216}$ Lin and co-workers reported Re-complex, Ru-complex and Ir-complex derived MOFs as single-site photocatalysts for $\mathrm{CO}_{2}$ reduction and water oxidation. ${ }^{205}$ More recently, a proton reduction photocatalyst is synthesized by chelating Pt on MOF-253 (oxophilic $\mathrm{Al}^{3+}$ coordinated with $2,2^{0}$-bipyridine-5,50-dicarboxylic linker) for $\mathrm{H}_{2}$ production under visible light. ${ }^{206}$

\subsection{Organic dye-sensitized MOF photocatalysts}

So far, tens of thousands of MOFs have been developed; however, most of them display limited visible light absorption capacity and poor photocatalytic performance. ${ }^{208}$ In order to increase the visible light adsorption capacity and enhance the photocatalytic performance, much effort has been devoted towards developing dye sen sitized MOFs for photocatalytic application. ${ }^{217}$ The metal oxide clusters in MOFs are typically composed of transition metal oxides that can be considered as semiconductor quantum dots. Employing suitable dye to sensitize these quantum dots is widely studied recently with the aim of enhancing the photocatalytic performance under visible light irradiation, particularly in water splitting. ${ }^{218-220}$ Organic dye sensitized MOF photocatalysts can be obtained by the impregnation method or introducing MOFs into organic dye solution. ${ }^{218,221}$

Our group constructed a novel $\mathrm{H}_{2}$ production system using Pt NP supported MOFs as photocatalysts, Rhodamine B (RhB) as a photosensitizer and triethanolamine as an electron donor. Considerable $\mathrm{H}_{2}$ is generated on $\mathrm{Pt} / \mathrm{MOF}$, which is much higher than that of $\mathrm{Pt} / \mathrm{TiO}_{2}$ and $\mathrm{Pt} / \mathrm{SiO}_{2}$, and this $\mathrm{H}_{2}$ production system exhibits remarkable stability; this can be repeated for five cycles without any decrease in catalytic activity. Such high catalytic performance towards $\mathrm{H}_{2}$ production is due to the synergistic effect between Pt/MOFs and organic dyes. Fig. 23 explains the

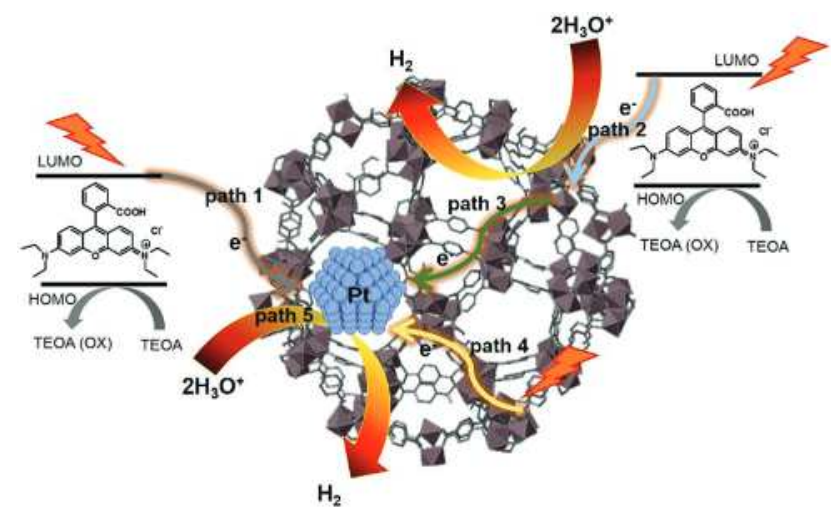

Fig. 23 Pt nanoparticle embedded MOFs as photocatalysts for $\mathrm{H}_{2}$ production in the presence of Rhodamine $B$ as a photosensitizer. possible reaction mechanism. The photogenerated electrons are first excited from the HOMO state to the LUMO state of RhB based on visible light irradiation; the excited electrons are subsequently injected into the LUMO state of the MOF and further transferred to the metal oxide clusters of the MOFs, and then finally gathered on the surfaces of the Pt NPs. Protons carried by water react with excited electrons to produce $\mathrm{H}_{2}$ on the surfaces of the Pt NPs and metal oxide clusters. In addition, the organic linker is also capable of harvesting visible light and leads to the generation of photo-electrons, which can be used to reduce protons. In this study, MOFs play vital roles in protecting RhB from self-degradation, preventing Pt NP aggregation, offering significant electron transportation pathways, and facilitating the proton diffusion. This work definitely shows the enormous potential of dye sensitized MOF photocatalysts for various photocatalytic reactions.

\subsection{Semiconductor/plasmonic material loaded MOF} photocatalysts

The integration of semiconductor/plasmonic materials and MOFs has attracted significant attention..$^{222,223}$ The large surface area can prevent the aggregation of semiconductor/plasmonic materials, and facilitate reagent diffusion and migration. The semiconducting properties of the MOFs can promote the transportation of photogenerated charges, leading to enhanced photocatalytic performance. ${ }^{224}$

Recently, our group reported the synthesis of plasmonic $\mathrm{Au} @ \mathrm{Pd}$ loaded onto titanium-doped zirconium based aminefunctionalized MOFs (UiO-66 $\left(\mathrm{Ti}_{\mathrm{x}} \mathrm{Zr}_{100} \mathrm{~F}_{\mathrm{W}}\right)$ ) (denoted $\mathrm{Au} @ \mathrm{Pd} / \mathrm{MOFs}$ ) by photocatalytically depositing Pd on the surfaces of Au nanoparticles. ${ }^{225}$ In this regard, MOFs display a vital role in the formation of Au@Pd NPs with a core-shell structure. Au@Pd with a core-shell structure is successfully synthesized and highly dispersed on the surfaces of the MOFs as observed by HAADF-STEM and EDX-line scanning (Fig. 24(a)). This is due to the large surfaces of the MOFs preventing the aggregation of metal NPs and
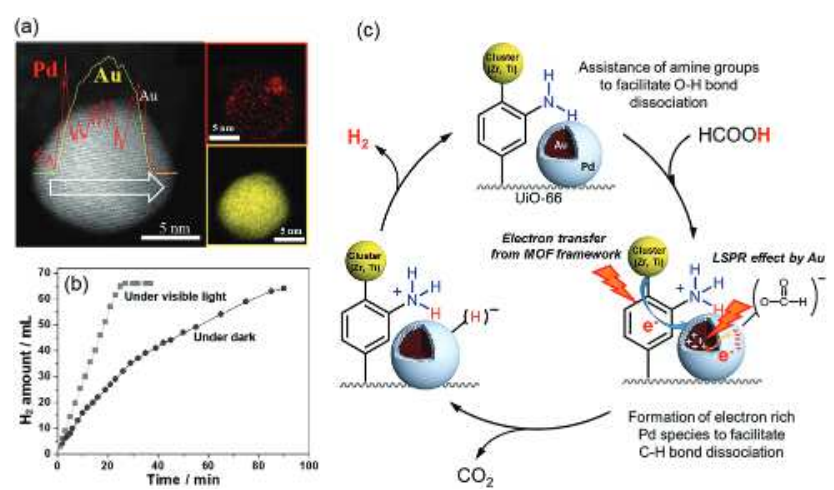

Fig. 24 (a) High-magnification EDX spectra of Pd and Au for an individual Au@Pd nanoparticle and cross-sectional EDX line profile on a single Au@Pd core-shell nanoparticle. (b) Amount of $\mathrm{H}_{2}$ produced in the FA dehydrogenation in the dark and under visible light irradiation (1 $4420 \mathrm{~nm}$ ). (c) The illustration of a possible reaction mechanism for the visible light enhanced $\mathrm{H}_{2}$ production from FA dehydrogenation over Au@Pd/UiO$66\left(\mathrm{Zr}_{85} \mathrm{Ti}_{15}\right)$ upon visible light irradiation. 
semiconducting properties transferring the photogenerated charges to the surfaces of the Au NPs. The as prepared Au@Pd/ MOF photocatalysts can strongly adsorb visible light over a wide range due to the LSPR effect of Au and the chromophore on the linker of the MOFs. The $\mathrm{H}_{2}$ amount generated by formic acid dehydrogenation over $\mathrm{Au} @ \mathrm{Pd} / \mathrm{MOF}$ is significantly increased under visible light irradiation compared to that under dark conditions (Fig. 24(b)). The enhanced activity of $\mathrm{Au} @ \mathrm{Pd} / \mathrm{UiO}-$ $66\left(\mathrm{Zr}_{85} \mathrm{Ti}_{15}\right)$ can be assigned to the synergistic effect between the MOFs and plasmonic Au@Pd NPs in the dissociation of the $\mathrm{O}-\mathrm{H}$ bond and the $\mathrm{C}-\mathrm{H}$ bond of formic acid. The visible-light enhanced $\mathrm{H}_{2}$ production rate of this hybrid photocatalyst is

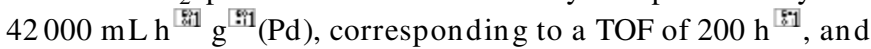
it can be recycled three times with a slight decrease in catalytic activity, suggesting considerable stability in FA dehydrogenation. We used monochromatic light $(I=400 \mathrm{~nm}$ or $480 \mathrm{~nm})$ and an LED lamp $(1=530 \mathrm{~nm})$ as a light source to investigate the synergistic effect between plasmonic Au@Pd nanoparticles and photoactive MOFs. It was found that the largest enhancement was observed using monochromatic light $(l=400 \mathrm{~nm})$. This can be explained by a linker-to-cluster charge-transfer mechanism (LCCT), in which the incident light $(1=400 \mathrm{~nm})$ is absorbed by the organic linker, and photo-excited electrons are transferred from the linker to the cluster. In the case of $\mathrm{Au} @ \mathrm{Pd}$ nanoparticle loaded MOFs, the photo-excited electrons are finally gathered on the surface of Au@Pd metal, which leads to the generation of electron rich Au@Pd NPs. A considerable enhancement was also observed under LED lamp $(1=530 \mathrm{~nm})$ irradiation. This can be ascribed to the positive LSPR effect of $\mathrm{Au}$ upon increasing the electron density of Pd. It was proven that the electron rich $\mathrm{Pd}$ can greatly promote the dissociation of the $\mathrm{C}-\mathrm{H}$ bond as evidenced by a kinetic isotope effect (KIE) study. The KIE study also suggested that the weakly basic $-\mathrm{NH}_{2}$ groups within the frameworks of the MOFs have positive effects on the $\mathrm{O}-\mathrm{H}$ bond cleavage. Therefore, the ratedetermining step ( $\mathrm{C}-\mathrm{H}$ bond dissociation) and $\mathrm{O}-\mathrm{H}$ bond dissociation are, respectively, promoted by the electron rich Pd generated by light irradiated on MOFs and plasmonic $\mathrm{Au} @ \mathrm{Pd}$ NPs and weakly basic $-\mathrm{NH}_{2}$. The roles of weakly basic $-\mathrm{NH}_{2}$, the LSPR effect, and optical responsive MOFs in improving $\mathrm{H}_{2}$ production from formic acid are illustrated in Fig. 24(c). This study suggests that MOFs can serve as a platform to design a novel photocatalyst by combining with other catalytic active compounds for various catalytic reactions under light irradiation

\subsection{Metal nanoparticles supported on MOFs}

MOFs hold great potential to improve the intrinsic catalytic activity of metal NPs for versatile redox reactions. Our group reported the synthesis of a $\mathrm{Ce}$ ion doped metal-organic framework (Ce-MOF) for significantly promoting the catalytic activity of $\mathrm{Pd}^{226}$ In this study, a mediator was introduced within the nodes of MOFs with the aim of promoting the photo-generated charge separation by a recycling $\left(\mathrm{Ce}^{4+} / \mathrm{Ce}^{3+}\right)$ redox, resulting in reduction of the photo-generated electron-hole recombination rate. Indeed, the intrinsic catalytic activity of $\mathrm{H}_{2}$ production from ammonia borane is enhanced on Ce doped MOFs under visible light irradiation. We also propose a general way to enhance the catalytic activity using non-noble metal NPs supported on MOFs. ${ }^{227}$ The TOFs of $\mathrm{Cu}$, Co and Ni/MOFs are comparable to or even higher than those of noble metal NPs already reported for $\mathrm{AB}$ hydrolysis. These studies provide a novel pathway for the design of new photocatalysts enabling efficient conversion of solar energy to chemical energy for promoting the metal NP driven redox reaction.

The study of the application of MOFs in photocatalysis has a bright future due to their unique structure; MOFs offer a way towards the development of advanced photocatalysts for solar energy conversion and environmental remediation. However, there are still some problems to be solved. First, MOFs are known to be unstable during the photocatalytic application. The coordination bonds between the metal oxide cluster and organic linker are weak, leading to poor stability of the MOFs. The development of stable MOFs is urgently required. Second, it is difficult to perform a high-throughput synthesis on a large scale. The common solvothermal methods is not effective for MOF fabrication on a large scale and with low cost. Looking for the cheap starting materials and the feasibility of fabrication methods with high yield should be explored. Finally, the photocatalytic performance of MOFs needs to be further improved in the case of practical application.

\section{Summary}

In this review, we introduced the concept of photocatalystbased functional materials prepared by utilizing the empty spaces of porous materials. The photocatalysts in the pore spaces are greatly influenced by a subtle change in the coordination structure and the reaction field environment (hydrophilicity/ hydrophobicity, electrostatic fields, etc.) in the vicinity of the active species, and they can exhibit unique activity and selectivity different from conventional semiconducting photocatalysts. The combination of pore spaces and photocatalysts can be applied not only to catalytic materials but also to hydrophilic/water repellent coatings. With light or microwave irradiation, it is also possible to syn thesize plasmonic nanometals and alloys, which can be further extended to composite materials designed for environmental uses and solar fuel harvesting. There is still great potential for nanoporous space materials with various structures and synthesis methods. New nanoporous materials having unprecedented compositions, frameworks, structures and sizes like MOFs are also actively developed. Research studies on novel functional photocatalysts having intrinsic features will be expanded, by combining the features of photocatalysts and porous materials skilfully to construct composite materials applicable to environmental purification and energy conversion.

\section{Conflicts of interest}

There are no conflicts to declare. 


\section{Acknowledgements}

The present work was supported by Grants-in-Aid for Scientific Research (No. 26220911, 25289289, 26630409, and 26620194) from the Japan Society for the Promotion of Science (JSPS) and MEXT. HY, KM and YK thank the MEXT program "Elements Strategy Initiative to Form Core Research Centers".

\section{Notes and references}

1 H. Yamashita and K. Mori, Chem. Lett., 2007, 36, 348-353.

2 K. Mori, H. Yamashita and M. Anpo, RSC Adv., 2012, 2, 3165-3172.

3 K. Mori and H. Yamashita, Chem. - Eur. J., 2016, 22, 11122-11137.

4 X. Qian, K. Fuku, Y. Kuwahara, T. Kamegawa, K. Mori and H. Yamashita, ChemSusChem, 2014, 7, 1528-1536.

5 M. Wen, K. Mori, Y. Kuwahara, T. C. An and H. Yamashita, Appl. Catal., B, 2017, 218, 555-569.

6 H. Cheng, K. Fuku, Y. Kuwahara, K. Mori and H. Yamashita, J. Mater. Chem. A, 2015, 3, 5244-5258.

7 A. Fujishima and K. Honda, Nature, 1972, 238, 37-38.

8 A. Kudo and Y. Miseki, Chem. Soc. Rev., 2009, 38, 253-278.

9 R. Eisenberg, Science, 2009, 324, 44-45.

10 T. Maschmeyer and M. Che, Angew. Chem., Int. Ed., 2010, 49, 1536-1539.

11 J. F. Lambert and M. Che, J. Mol. Catal. A: Chem., 2000, 162, $5-18$.

12 A. Corma, J. Catal., 2003, 216, 298-312.

13 Y. Wan and D. Zhao, Chem. Rev., 2007, 107, 2821-2860.

14 K. S. W. Sing, D. H. Everett, R. A. W. Haul, L. Moscou, R. A. Pierotti, J. Rouquerol and T. Siemieniewska, Pure Appl. Chem., 1985, 57, 603-619.

15 M. Che, K. Mori and H. Yamashita, Proc. R. Soc. A, 2012, 468, 2113-2128.

16 X. Wei, K.-X. Wang, X.-X. Guo and J.-S. Chen, Proc. R. Soc. A, 2012, 468, 2099-2112.

17 J. Lee, O. K. Farha, J. Roberts, K. A. Scheidt, S. T. Nguyen and J. T. Hupp, Chem. Soc. Rev., 2009, 38, 1450-1459.

18 T. R. Cook, Y.-R. Zheng and P. J. Stang, Chem. Rev., 2013, $113,734-777$.

19 K. Fuku, R. Hayashi, S. Takakura, T. Kamegawa, K. Mori and H. Yamashita, Angew. Chem., Int. Ed., 2013, 52, 7446-7450.

20 W. Hou and S. B. Cronin, Adv. Funct. Mater., 2013, 23, 1612-1619.

21 H. Yamashita, K. Mori, S. Shironita and Y. Horiuchi, Catal. Surv. Asia, 2008, 12, 88-100.

22 H. Yamashita and M. Anpo, Catal. Surv. Asia, 2004, 8, 35-45.

23 H. Yamashita and M. Anpo, Curr. Opin. Solid State Mater. Sci., 2003, 7, 471-481.

24 M. Anpo and J. M. Thomas, Chem. Commun., 2006, 3273-3278

25 H. Yamashita, S. Kawasaki, Y. Ichihashi, M. Harada, M. Takeuchi, M. Anpo, G. Stewart, M. A. Fox, C. Louis and M. Che, J. Phys. Chem. B, 1998, 102, 5870-5875.
26 J. M. Thomas and G. Sankar, Acc. Chem. Res., 2001, 34, $571-581$.

27 K. Mori, Y. Kondo, S. Morimoto and H. Yamashita, J. Phys. Chem. C, 2008, 112, 397-404.

28 M. Anpo, H. Yamashita, Y. Ichihashi, Y. Fujii and M. Honda, J. Phys. Chem. B, 1997, 101, 2632-2636.

29 K. Ikeue, H. Yamashita, M. Anpo and T. Takewaki, J. Phys. Chem. B, 2001, 105, 8350-8355.

30 Y. Sohn, W. Huang and F. Taghipour, Appl. Surf. Sci., 2017, 396, 1696-1711.

31 M. Anpo, N. Aikawa, Y. Kubokawa, M. Che, C. Louis and E. Giamello, J. Phys. Chem., 1985, 89, 5017-5021.

32 M. Anpo, N. Aikawa, Y. Kubokawa, M. Che, C. Louis and E. Giamello, J. Phys. Chem., 1985, 89, 5689-5694.

33 H. Yamashita, Y. Ichihashi, M. Anpo, M. Hashimoto, C. Louis and M. Che, J. Phys. Chem., 1996, 100, 16041-16044.

34 N. U. Zhanpeisov, M. Matsuoka, H. Yamashita and M. Anpo, J. Phys. Chem. B, 1998, 102, 6915-6920.

35 M. Anpo, S. G. Zhang, S. Higashimoto, M. Matsuoka, H. Yamashita, Y. Ichihashi, Y. Matsumura and Y. Souma, J. Phys. Chem. B, 1999, 103, 9295-9301.

36 S. Higashimoto, M. Matsuoka, H. Yamashita, M. Anpo, O. Kitao, H. Hidaka, M. Che and E. Giamello, J. Phys. Chem. B, 2000, 104, 10288-10292.

37 S. Higashimoto, Y. Hu, R. Tsumura, K. Iino, M. Matsuoka, H. Yamashita, Y. G. Shul, M. Che and M. Anpo, J. Catal., 2005, 235, 272-278.

38 H. Yamashita, K. Yoshizawa, M. Ariyuki, S. Higashimoto, M. Che and M. Anpo, Chem. Commun., 2001, 435-436.

39 C. Murata, H. Yoshida and T. Hattori, Chem. Commun., 2001, 2412-2413.

40 H. Yamashita, K. Kida, K. Ikeue, Y. Kanazawa, K. Yoshizawa and M. Anpo, in Std. Surf. Sci. Catal., ed. S.-E. Park, R. Ryoo, W.-S. Ahn, C. W. Lee and J.-S. Chang, Elsevier, 2003, vol. 146, pp. 597-600.

41 Y. Horiuchi, K. Mori, N. Nishiyama and H. Yamashita, Chem. Lett., 2008, 37, 748-749.

42 K. Mori, Y. Miura, S. Shironita and H. Yamashita, Langmuir, 2009, 25, 11180-11187.

43 K. Mori, T. Araki, S. Shironita, J. Sonoda and H. Yamashita, Catal. Lett., 2009, 131, 337-343.

44 K. Mori and H. Yamashita, Phys. Chem. Chem. Phys., 2010, 12, 14420-14432.

45 K. Mori, K. Sugihara, Y. Kondo, T. Takeuchi, S. Morimoto and H. Yamashita, J. Phys. Chem. C, 2008, 112, 16478-16483.

46 S. Okada, K. Mori, T. Kamegawa, M. Che and H. Yamashita, Chem. - Eur. J., 2011, 17, 9047-9051.

47 S. Okada, S. Ikurumi, T. Kamegawa, K. Mori and H. Yamashita, J. Phys. Chem. C, 2012, 116, 14360-14367.

48 H. Yamashita, M. Matsuoka, K. Tsuji, Y. Shioya, M. Anpo and M. Che, J. Phys. Chem., 1996, 100, 397-402.

49 W.-S. Ju, M. Matsuoka, K. Iino, H. Yamashita and M. Anpo, J. Phys. Chem. B, 2004, 108, 2128-2133.

50 A. Maldotti, R. Amadelli, C. Bartocci, V. Carassiti, E. Polo and G. Varani, Coord. Chem. Rev., 1993, 125, 143-154. 
51 A. J. Esswein and D. G. Nocera, Chem. Rev., 2007, 107, 4022-4047.

52 C. K. Prier, D. A. Rankic and D. W. C. MacMillan, Chem. Rev., 2013, 113, 5322-5363.

53 X. Liu, S. Inagaki and J. Gong, Angew. Chem., Int. Ed., 2016, 55, 14924-14950.

54 N. Mizoshita, T. Tani and S. Inagaki, Chem. Soc. Rev., 2011, 40, 789-800.

55 M. Ogawa and K. Kuroda, Chem. Rev., 1995, 95, 399-438.

56 W. J. Youngblood, S.-H. A Lee, K. Maeda and T. E. Mallouk, Acc. Chem. Res., 2009, 42, 1966-1973.

57 R. Kuriki and K. Maeda, Phys. Chem. Chem. Phys., 2017, 19, 4938-4950.

58 J. C. Fierro-Gonzalez, S. Kuba, Y. Hao and B. C. Gates, J. Phys. Chem. B, 2006, 110, 13326-13351.

59 H. S. Kim, T. C. T. Pham and K. B. Yoon, Chem. Commun., 2012, 48, 4659-4673.

60 H. S. Kim and K. B. Yoon, Coord. Chem. Rev., 2014, 263-264, 239-256.

61 K. Mori, K. Kagohara and H. Yamashita, J. Phys. Chem. C, 2008, 112, 2593-2600.

62 M. Martis, K. Mori and H. Yamashita, Dalton Trans., 2014, 43, 1132-1138.

63 K. Mori, M. Kawashima, K. Kagohara and H. Yamashita, J. Phys. Chem. C, 2008, 112, 19449-19455.

64 Y. Kuwahara, K. Nishizawa, T. Nakajima, T. Kamegawa, K. Mori and H. Yamashita, J. Am. Chem. Soc., 2011, 133, 12462-12465.

65 K. Mori, M. Tottori, K. Watanabe, M. Che and H. Yamashita, J. Phys. Chem. C, 2011, 115, 21358-21362.

66 K. Mori, K. Watanabe, M. Kawashima, M. Che and H. Yamashita, J. Phys. Chem. C, 2011, 115, 1044-1050.

67 K. Mori, K. Watanabe, Y. Terai, Y. Fujiwara and H. Yamashita, Chem. - Eur. J., 2012, 18, 11371-11378.

68 K. Mori, K. Watanabe, K. Fuku and H. Yamashita, Chem. - Eur. J., 2012, 18, 415-418.

69 K. Mori, M. Kawashima, M. Che and H. Yamashita, Angew. Chem., Int. Ed., 2010, 49, 8598-8601.

70 K. Mori, H. Tanaka, M. Dojo, K. Yoshizawa and H. Yamashita, Chem. - Eur. J., 2015, 21, 12085-12092.

71 K. Mori, Y. Kubota and H. Yamashita, Chem. - Asian J., 2013, 8, 3207-3213.

72 S. Fukuzumi, Y.-M. Lee and W. Nam, Coord. Chem. Rev., 2018, 355, 54-73.

73 K. Mori, H. Kakudo and H. Yamashita, ACS Catal., 2014, 4, 4129-4135.

74 T. Nakato, H. Edakubo and T. Shimomura, Microporous Mesoporous Mater., 2009, 123, 280-288.

75 J. Ma, J. Wu, J. Zheng, L. Liu, D. Zhang, X. Xu, X. Yang and Z. Tong, Microporous Mesoporous Mater., 2012, 151, 325-329.

76 M. Gasperin and M.-T. le Bihan, J. Solid State Chem., 1980, $33,83-89$.

77 K. Mori, S. Ogawa, M. Martis and H. Yamashita, J. Phys. Chem. C, 2012, 116, 18873-18877.

78 M. Kawashima, K. Mori, J. Aoyama and H. Yamashita, Bull. Chem. Soc. Jpn., 2014, 87, 874-881.
79 M. Wen, K. Mori, Y. Kuwahara and H. Yamashita, ChemCatChem, 2015, 7, 3519-3525.

80 A. Fujishima, T. N. Rao and D. A. Tryk, J. Photochem. Photobiol., C, 2000, 1, 1-21.

$81 \mathrm{X}$. Chen and S. S. Mao, Chem. Rev., 2007, 107, 2891-2959.

82 M. R. Hoffmann, S. T. Martin, W. Choi and D. W. Bahnemann, Chem. Rev., 1995, 95, 69-96.

83 A. L. Linsebigler, G. Lu and J. T. Yates, Chem. Rev., 1995, 95, 735-758.

84 H. Yamashita, H. Nose, Y. Kuwahara, Y. Nishida, S. Yuan and K. Mori, Appl. Catal., A, 2008, 350, 164-168.

85 C. Ooka, H. Yoshida, M. Horio, K. Suzuki and T. Hattori, Appl. Catal., B, 2003, 41, 313-321.

86 Y. Kuwahara and H. Yamashita, J. Mater. Chem., 2011, 21, 2407-2416.

87 Y. Kuwahara, J. Aoyama, K. Miyakubo, T. Eguchi, T. Kamegawa, K. Mori and H. Yamashita, J. Catal., 2012, 285, 223-234.

88 Y. Kuwahara, Y. Magatani and H. Yamashita, Rapid Commun. Photosci., 2015, 4, 19-21.

89 T. Kamegawa, R. Kido, D. Yamahana and H. Yamashita, Microporous Mesoporous Mater., 2013, 165, 142-147.

90 T. Kamegawa, Y. Ishiguro, R. Kido and H. Yamashita, Molecules, 2014, 19, 16477-16488.

91 T. Kasahara, K. Inumaru and S. Yamanaka, Microporous Mesoporous Mater., 2004, 76, 123-130.

92 Y. Magatani, Y. Kuwahara, K. Nishizawa and H. Yamashita, ChemistrySelect, 2017, 2, 4332-4337.

93 Y. Kuwahara, T. Kamegawa, K. Mori and H. Yamashita, Chem. Commun., 2008, 4783-4785.

94 Y. Kuwahara, K. Maki, Y. Matsumura, T. Kamegawa, K. Mori and H. Yamashita, J. Phys. Chem. C, 2009, 113, 1552-1559.

95 T. Nonami, H. Hase and K. Funakoshi, Catal. Today, 2004, 96, 113-118.

96 A. Nakajima, K. Takakuwa, Y. Kameshima, M. Hagiwara, S. Sato, Y. Yamamoto, N. Yoshida, T. Watanabe and K. Okada, J. Photochem. Photobiol., A, 2006, 177, 94-99.

97 Y. Kuwahara, T. Yamanishi, T. Kamegawa, K. Mori and H. Yamashita, J. Phys. Chem. B, 2011, 115, 10335-10345.

98 X. F. Qian, T. Kamegawa, K. Mori, H. X. Li and H. Yamashita, J. Phys. Chem. C, 2013, 117, 19544-19551.

99 T. Torimoto, Y. Okawa, N. Takeda and H. Yoneyama, J. Photochem. Photobiol., A 1997, 103, 153-157.

100 Q. Xiang, J. Yu and M. Jaroniec, Chem. Soc. Rev., 2012, 41, 782-796.

101 W. Donphai, T. Kamegawa, M. Chareonpanich, K. Nueangnoraj, H. Nishihara, T. Kyotani and H. Yamashita, Phys. Chem. Chem. Phys., 2014, 16, 25004-25007.

102 Y. Liu, J. I. Dadap, D. Zimdars and K. B. Eisenthal, J. Phys. Chem. B, 1999, 103, 2480-2486.

103 I. A Janković, Z. V. Šaponjić, M. I. Čomor and J. M. Nedeljković, J. Phys. Chem. C, 2009, 113, 12645-12652.

104 T. Kamegawa, H. Seto, S. Matsuura and H. Yamashita, ACS Appl. Mater. Interfaces, 2012, 4, 6635-6639. 
105 T. Kamegawa, S. Matsuura, H. Seto and H. Yamashita, Angew. Chem., Int. Ed., 2013, 52, 916-919.

106 T. Kamegawa, D. Yamahana and H. Yamashita, J. Phys. Chem. C, 2010, 114, 15049-15053.

107 M. Sadakane, C. Takahashi, N. Kato, H. Ogihara, Y. Nodasaka, Y. Doi, Y. Hinatsu and W. Ueda, Bull. Chem. Soc. Jpn., 2007, 80, 677-685.

108 A. Stein, B. E. Wilson and S. G. Rudisill, Chem. Soc. Rev., 2013, 42, 2763-2803.

109 K. R. Phillips, G. T. England, S. Sunny, E. Shirman, T. Shirman, N. Vogel and J. Aizenberg, Chem. Soc. Rev., 2016, 45, 281-322.

110 T. Kamegawa, N. Suzuki, M. Che and H. Yamashita, Langmuir, 2011, 27, 2873-2879.

111 T. Kamegawa, S. Tanaka, H. Seto, D. Zhou and H. Yamashita, Phys. Chem. Chem. Phys., 2013, 15, 13323-13328.

112 T. Kamegawa, T. Ando, Y. Ishiguro and H. Yamashita, Bull. Chem. Soc. Jpn., 2015, 88, 572-574.

113 T. Kamegawa, Y. Ishiguro, H. Seto and H. Yamashita, J. Mater. Chem. A, 2015, 3, 2323-2330.

114 G. J. d. A A. Soler-Illia, C. Sanchez, B. Lebeau and J. Patarin, Chem. Rev., 2002, 102, 4093-4138.

115 Q. Zhang, I. Lee, J. Ge, F. Zaera and Y. Yin, Adv. Funct. Mater., 2010, 20, 2201-2214.

116 Y. Ide, Y. Koike and M. Ogawa, J. Colloid Interface Sci., 2011, 358, 245-251.

117 T. Kamegawa, Y. Ishiguro, Y. Magatani and H. Yamashita, J. Nanosci. Nanotechnol., 2016, 16, 9273-9277.

118 A. M. El-Toni, M. A Habila, J. P. Labis, Z. A. ALOthman, M. Alhoshan, A. A. Elzatahry and F. Zhang, Nanoscale, 2016, 8, 2510-2531.

119 R. Purbia and S. Paria, Nanoscale, 2015, 7, 19789-19873.

120 Y. Kuwahara, T. Ando, H. Kango and H. Yamashita, Chem. - Eur. J., 2017, 23, 380-389.

121 K. Fujiwara, Y. Kuwahara, Y. Sumida and H. Yamashita, J. Mater. Chem. A, 2017, 5, 25431-25437.

122 S. Ikeda, Y. Ikoma, H. Kobayashi, T. Harada, T. Torimoto, B. Ohtani and M. Matsumura, Chem. Commun., 2007, 3753-3755.

123 S. Ikeda, H. Kobayashi, Y. Ikoma, T. Harada, T. Torimoto, B. Ohtani and M. Matsumura, Phys. Chem. Chem. Phys., 2007, 9, 6319-6326.

124 S. Ikeda, H. Kobayashi, T. Sugita, Y. Ikoma, T. Harada and M. Matsumura, Appl. Catal., A, 2009, 363, 216-220.

125 G. Li, E. T. Kang, K. G. Neoh and X. Yang, Langmuir, 2009, 25, 4361-4364.

126 Y. Ren, M. Chen, Y. Zhang and L. Wu, Langmuir, 2010, 26, 11391-11396.

127 Y. Kuwahara, Y. Sumida, K. Fujiwara and H. Yamashita, ChemCatChem, 2016, 8, 2781-2788.

128 K. Fujiwara, Y. Kuwahara, Y. Sumida and H. Yamashita, Langmuir, 2017, 33, 6314-6321.

129 K. Fujiwara, Y. Kuwahara, Y. Sumida and H. Yamashita, Langmuir, 2017, 33, 288-295.

130 Y. Horiuchi, H. Ura, T. Kamegawa, K. Mori and H. Yamashita, Appl. Catal., A, 2010, 387, 95-99.
131 X. Feng and L. Jiang, Adv. Mater., 2006, 18, 3063-3078.

132 P. Roach, N. J. Shirtcliffe and M. I. Newton, Soft Matter, 2008, 4, 224.

133 B. Xin and J. Hao, Chem. Soc. Rev., 2010, 39, 769-782.

134 T. Darmanin and F. Guittard, J. Mater. Chem. A, 2014, 2, 16319-16359.

135 X. Chen and S. S. Mao, Chem. Rev., 2007, 107, 2891-2959.

136 A. Kubacka, M. Fernández-García and G. Colón, Chem. Rev., 2012, 112, 1555-1614.

137 R. Wang, K. Hashimoto, A. Fujishima, M. Chikuni, E. Kojima, A Kitamura, M. Shimohigoshi and T. Watanabe, Nature, 1997, 388, 431-432.

138 R. Wang, K. Hashimoto, A. Fujishima, M. Chikuni, E. Kojima, A Kitamura, M. Shimohigoshi and T. Watanabe, Adv. Mater., 1998, 10, 135-138.

139 J. Liu, M. Li, J. Wang, Y. Song, L. Jiang, T. Murakami and A. Fujishima, Environ. Sci. Technol., 2009, 43, 9425-9431.

140 T. Kawahara, Y. Konishi, H. Tada, N. Tohge, J. Nishii and S. Ito, Angew. Chem., Int. Ed., 2002, 41, 2811-2813.

141 X. Chen, Z. Li, J. Ye and Z. Zou, Chem. Mater., 2010, 22, 3583-3585.

142 G. Kaune, M. Memesa, R. Meier, M. A. Ruderer, A. Diethert, S. V. Roth, M. Dacunzi, J. S. Gutmann and P. MüllerBuschbaum, ACS Appl. Mater. Interfaces, 2009, 1, 2862-2869.

143 T. Kamegawa, N. Suzuki and H. Yamashita, Energy Environ. Sci., 2011, 4, 1411-1416.

144 T. Kamegawa, N. Suzuki and H. Yamashita, Chem. Lett., 2009, 38, 610-611.

145 H. Y. Lee, Y. H. Park and K. H. Ko, Langmuir, 2000, 16, 7289-7293.

146 J. M. Thomas, Angew. Chem., Int. Ed., 1999, 38, 3588-3628.

147 A Corma, Chem. Rev., 1997, 97, 2373-2419.

148 M. Ogawa, Chem. Commun., 1996, 1149-1150.

149 N. Nishiyama, S. Tanaka, Y. Egashira, Y. Oku and K. Ueyama, Chem. Mater., 2002, 14, 4229-4234.

150 H. Yamashita, S. Nishio, I. Katayama, N. Nishiyama and H. Fujii, Catal. Today, 2006, 111, 254-258.

151 H. Yamashita, Y. Horiuchi, S. Imaoka, S. Nishio, N. Nishiyama and K. Mori, Catal. Today, 2008, 132, 146-152.

152 H. Yamashita, S. Nishio, S. Imaoka, M. Shimada, K. Mori, T. Tanaka and N. Nishiyama, Top. Catal., 2008, 47, 116-121.

153 Y. Horiuchi, H. Ura, T. Kamegawa, K. Mori and H. Yamashita, J. Mater. Chem., 2011, 21, 236-241.

154 Y. Horiuchi, H. Ura, T. Kamegawa, K. Mori and H. Yamashita, J. Phys. Chem. C, 2011, 115, 15410-15415.

155 T. Kamegawa, Y. Masuda, N. Suzuki, Y. Horiuchi and H. Yamashita, ACS Appl. Mater. Interfaces, 2011, 3, 4561-4565.

156 Y. Horiuchi, T. Kamegawa, K. Mori, H. Yamashita and N. Nishiyama, e-J. Surf. Sci. Nanotechnol., 2009, 7, 141-144.

157 K. Mori, S. Imaoka, S. Nishio, Y. Nishiyama, N. Nishiyama and H. Yamashita, Microporous Mesoporous Mater., 2007, 101, 288-295.

158 Y. Horiuchi and H. Yamashita, Appl. Catal., A, 2011, $400,1-8$. 
159 H. Yamashita, K. Mori, S. Shironita and Y. Horiuchi, Catal Surv. Asia, 2008, 12, 88-100.

160 D. Öner and T. J. McCarthy, Langmuir, 2000, 16, 7777-7782.

161 P. Aussillous and D. Quéré, Nature, 2001, 411, 924-927.

162 A. Steele, I. Bayer and E. Loth, Nano Lett., 2009, 9, 501-505.

163 T. Onda, S. Shibuichi, N. Satoh and K. Tsujii, Langmuir, 1996, 12, 2125-2127.

164 A. Nakajima, A. Fujishima, K. Hashimoto and T. Watanabe, Adv. Mater., 1999, 11, 1365-1368.

165 J. Genzer and K. Efimenko, Science, 2000, 290, 2130-2133.

166 D. Schondelmaier, S. Cramm, R. Klingeler, J. Morenzin, C. Zilkens and W. Eberhardt, Langmuir, 2002, 18, 6242-6245.

167 Y. Horiuchi, K. Fujiwara, T. Kamegawa, K. Mori and H. Yamashita, J. Mater. Chem., 2011, 21, 8543-8546.

168 H. Yamashita, K. Kida, K. Ikeue, Y. Kanazawa, K. Yoshizawa and M. Anpo, Stud. Surf. Sci. Catal., 2002, 146, 597-600.

169 Y. Horiuchi, Y. Shimizu, T. Kamegawa, K. Mori and H. Yamashita, Phys. Chem. Chem. Phys., 2011, 13, 6309-6314.

170 S. Shironita, T. Takasaki, T. Kamegawa, K. Mori and H. Yamashita, Top. Catal., 2010, 53, 218-223.

171 X. Feng, J. Zhai and L. Jiang, Angew. Chem., Int. Ed., 2005, 44, 5115-5118.

172 Q. Fu, G. V. R. Rao, S. B. Basame, D. J. Keller, K. Artyushkova, J. E. Fulghum and G. P. López, J. Am. Chem. Soc., 2004, 126, 8904-8905.

173 G. K. Jennings and E. L. Brantley, Adv. Mater., 2004, 16, 1983-1994.

174 J. Lahann, S. Mitragotri, T. N. Tran, H. Kaido, J. Sundaram, I. S. Choi, S. Hoffer, G. A Somorjai and R. Langer, Science, 2003, 299, 371-374.

175 S. Wang, H. Liu, D. Liu, X. Ma, X. Fang and L. Jiang, Angew. Chem., Int. Ed., 2007, 46, 3915-3917.

176 X. Zhang, M. Jin, Z. Liu, D. A. Tryk, S. Nishimoto, T. Murakami and A Fujishima, J. Phys. Chem. C, 2007, 111, 14521-14529.

177 F. Zhou and W. T. S. Huck, Chem. Commun., 2005, 5999-6001.

178 T. Kamegawa, Y. Shimizu and H. Yamashita, Adv. Mater., 2012, 24, 3697-3700.

179 T. Kamegawa, K. Irikawa and H. Yamashita, Chem. Lett., 2015, 44, 509-511.

180 T. Kamegawa, K. Irikawa and H. Yamashita, Sci. Rep., 2017, 7, 13628-13635.

181 X. Liu, J. Iocozzia, Y. Wang, X. Cui, Y. Chen, S. Zhao, Z. Li and Z. Lin, Energy Environ. Sci., 2017, 10, 402-434.

182 X. Zhang, Y. L. Chen, R. S. Liu and D. P. Tsai, Rep. Prog. Phys., 2013, 76, 046401.

183 X. Zhou, G. Liu, J. Yu and W. Fan, J. Mater. Chem., 2012, 22, 21337-21354.

184 Q. Xiang, B. Cheng and J. Yu, Angew. Chem., Int. Ed., 2015, 54, 11350-11366.

185 C. Clavero, Nat. Photonics, 2014, 8, 95-103.

186 S. Yu, A. J. Wilson, G. Kumari, X. Zhang and P. K. Jain, ACS Energy Lett., 2017, 2, 2058-2070.
187 M. Rycenga, C. M. Cobley, J. Zeng, W. Li, C. H. Moran, Q. Zhang, D. Qin and Y. Xia, Chem. Rev., 2011, 111, 3669-3712.

188 M. R. Langille, M. L. Personick and C. A Mirkin, Angew. Chem., Int. Ed., 2013, 52, 13910-13940.

189 K. Mori, P. Verma, R. Hayashi, K. Fuku and H. Yamashita, Chem. - Eur. J., 2015, 21, 11885-11893.

190 M. Chandra and Q. Xu, J. Power Sources, 2006, 156, 190-194.

191 A. Gutowska, L. Li, Y. Shin, C. M. Wang, X. S. Li, J. C. Linehan, R. S. Smith, B. D. Kay, B. Schmid, W. Shaw, M. Gutowski and T. Autrey, Angew. Chem., Int. Ed., 2005, 44, 3578-3582.

192 P. Verma, Y. Kuwahara, K. Mori and H. Yamashita, J. Mater. Chem. A, 2015, 3, 18889-18897.

193 P. Verma, Y. Kuwahara, K. Mori and H. Yamashita, J. Mater. Chem. A, 2016, 4, 10142-10150.

194 P. Verma, Y. Kuwahara, K. Mori and H. Yamashita, Catal. Sci. Technol., 2017, 7, 2551-2558.

195 P. Verma, K. Yuan, Y. Kuwahara, K. Mori and H. Yamashita, Appl. Catal., B, 2018, 223, 10-15.

196 P. Verma, Y. Kuwahara, K. Mori and H. Yamashita, Chem. - Eur. J., 2017, 23, 3616-3622.

197 A. Naldoni, F. Riboni, U. Guler, A. Boltasseva, V. M. Shalaev and A. V. Kildishev, Nanophotonics, 2016, 5, 112-133.

198 W. Ye, R. Long, H. Huang and Y. Xiong, J. Mater. Chem. C, 2017, 5, 1008-1021.

199 X. Zhang, X. Ke and J. Yao, J. Mater. Chem. A, 2018, 6, 1941-1966.

200 S. B. Wang and X. C. Wang, Small, 2015, 11, 3097-3112.

201 T. Zhang and W. B. Lin, Chem. Soc. Rev., 2014, 43, 5982-5993.

202 J. L. Wang, C. Wang and W. B. Lin, ACS Catal., 2012, 2, 2630-2640.

203 K. K. Tanabe and S. M. Cohen, Chem. Soc. Rev., 2011, 40, 498-519.

204 Y. Li, H. Xu, S. X. Ouyang and J. H. Ye, Phys. Chem. Chem. Phys., 2016, 18, 7563-7572.

205 C. Wang, Z. G. Xie, K. E. deKrafft and W. L. Lin, J. Am. Chem. Soc., 2011, 133, 13445-13454.

206 T. H. Zhou, Y. H. Du, A. Borgna, J. D. Hong, Y. B. Wang, J. Y. Han, W. Zhang and R. Xu, Energy Environ. Sci., 2013, 6, 3229-3234.

207 M. Alvaro, E. Carbonell, B. Ferrer, F. Xamena and H. Garcia, Chem. - Eur. J., 2007, 13, 5106-5112.

208 Y. Horiuchi, T. Toyao, M. Saito, K. Mochizuki, M. Iwata, H. Higashimura, M. Anpo and M. Matsuoka, J. Phys. Chem. C, 2012, 116, 20848-20853.

209 Y. H. Fu, D. R. Sun, Y. J. Chen, R. K. Huang, Z. X. Ding, X. Z. Fu and Z. H. Li, Angew. Chem., Int. Ed., 2012, 51, 3364-3367.

210 G. A. Filonenko, R. van Putten, E. N. Schulpen, E. J. M. Hensen and E. A. Pidko, ChemCatChem, 2014, 6, $1526-1530$.

211 M. C. Wen, K. Mori, Y. Kuwahara and H. Yamashita, ChemCatChem, 2015, 7, 3519-3525. 
212 C. Wang, K. E. deKrafft and W. B. Lin, J. Am. Chem. Soc., 2012, 134, 7211-7214.

213 T. Toyao, M. Saito, S. Dohshi, K. Mochizuki, M. Iwata, H. Higashimura, Y. Horiuchi and M. Matsuoka, Chem. Commun., 2014, 50, 6779-6781.

214 S. Pullen, H. H. Fei, A. Orthaber, S. M. Cohen and S. Ott, J. Am. Chem. Soc., 2013, 135, 16997-17003.

215 A. Fateeva, P. A. Chater, C. P. Ireland, A. A. Tahir, Y. Z. Khimyak, P. V. Wiper, J. R. Darwent and M. J. Rosseinsky, Angew. Chem., Int. Ed., 2012, 51, 7440-7444.

216 J. D. Evans, C. J. Sumby and C. J. Doon an, Chem. Soc. Rev., 2014, 43, 5933-5951.

217 M. C. Wen, K. Mori, Y. Kuwahara, T. C. An and H. Yamashita, Appl. Catal., B, 2017, 218, 555-569.

218 J. He, J. Q. Wang, Y. J. Chen, J. P. Zhang, D. L. Duan, Y. Wang and Z. Y. Yan, Chem. Commun., 2014, 50, 7063-7066.

219 R. Wang, X-L. Liu, M.-Y. Zhang, Y.-P. Yuan and C. Xue, APL Mater., 2015, 3, 104403.
220 W. L. Zhen, H. B. Gao, B. Tian, J. T. Ma and G. X. Lu, ACS Appl. Mater. Interfaces, 2016, 8, 10808-10819.

221 M. C. Wen, K. Mori, T. Kamegawa and H. Yamashita, Chem. Commun., 2014, 50, 11645-11648.

222 K. M. Choi, D. Kim, B. Rungtaweevoranit, C. A. Trickett, J. T. D. Barmanbek, A. S. Alshammari, P. Yang and O. M. Yaghi, J. Am. Chem. Soc., 2017, 139, 356-362.

223 L. J. Shen, M. B. Luo, Y. H. Liu, R. W. Liang, F. F. Jing and L. Wu, Appl. Catal., B, 2015, 166, 445-453.

224 C. W. Zhao, Y. A. Li, X. R. Wang, G. J. Chen, Q. K. Liu, J. P. Ma and Y. B. Dong, Chem. Commun., 2015, 51, 15906-15909.

225 M. C. Wen, K. Mori, Y. Kuwahara and H. Yamashita, ACS Energy Lett., 2017, 2, 1-7.

226 M. C. Wen, Y. Kuwahara, K. Mori, D. Q. Zhang, H. X. Li and H. Yamashita, J. Mater. Chem. A, 2015, 3, 14134-14141.

227 M. C. Wen, Y. Cui, Y. Kuwahara, K. Mori and H. Yamashita, ACS Appl. Mater. Interfaces, 2016, 8, 21278-21284. 